\title{
CONTRIBUIÇÃO PARA A DEFINIÇÃO DE CRITÉRIOS PARA O DIMENSIONAMENTO DA LIGAÇÃO ENTRE PEÇAS ESTRUTURAIS DE MADEIRA POR CHAPAS METÁLICAS COM DENTES ESTAMPADOS
}

\author{
Johnny Soares de Carvalho
}

\begin{abstract}
Dissertação apresentada à Escola de Engenharia de São Carlos, da Universidade de São Paulo, como parte dos requisitos para obtenção do título de Mestre em Engenharia de Estruturas.
\end{abstract}

Orientador: Prof. Dr. Francisco Antonio Rocco Lahr 
À minha esposa Carolina e aos meus pais Cristina e Edson 


\section{AGRADECIMENTOS}

Acima de tudo a Deus, que em sua infinita bondade e misericórdia me deu a força e a inteligência necessárias para que eu pudesse realizar este trabalho.

Agradeço à minha esposa Carolina que mesmo em momentos difíceis sempre me apoiou, me incentivou e se mostrou verdadeiramente amiga, companheira - uma grande mulher. Eu te amo!

Muito obrigado aos meus pais que, com certeza, nunca duvidaram que a realização deste sonho seria possível. Amo vocês!

À Ariel, Jasmim e ao Pitucho pelo companheirismo e alegria que sempre demonstraram.

Ao Professor Rocco (Chico) que, mais do que um orientador, mostrou-se como sempre um grande amigo, como um segundo pai pra mim. Valeu!

Aos Professores Calil e Dias que fizeram parte da minha formação profissional e que direta ou indiretamente nos auxiliaram na elaboração deste trabalho.

A todos os pós-graduandos, funcionários e amigos do LaMEM, que de alguma forma deram sua parcela de contribuição para que este projeto se tornasse uma realidade, o meu muito obrigado.

À Marta Salatiel pela amizade dedicada, pela disposição e por sua competência na realização da revisão gramatical deste trabalho.

À FAPESP, entidade que nos forneceu os subsídios necessários para a realização dessa pesquisa. 


\section{SUMÁRIO}

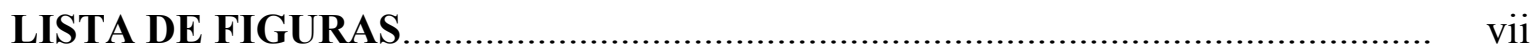

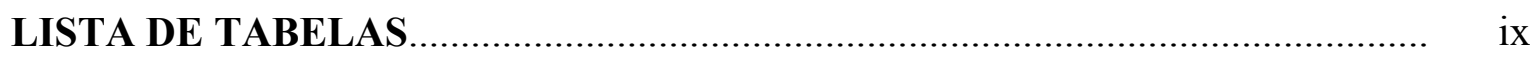

LISTA DE SIGLAS E ABREVIATURAS............................................... xiv

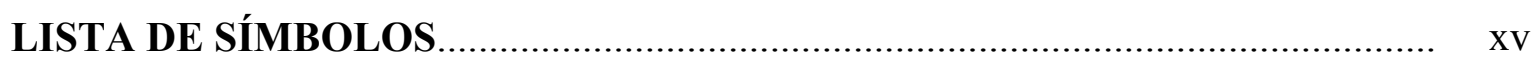

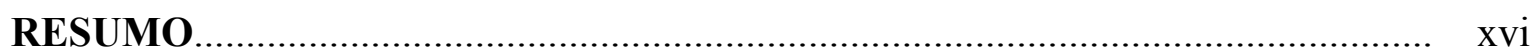

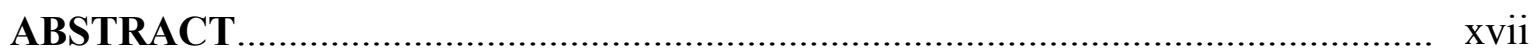

1. INTRODUÇÃ

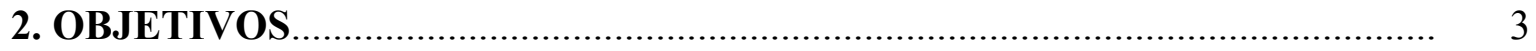

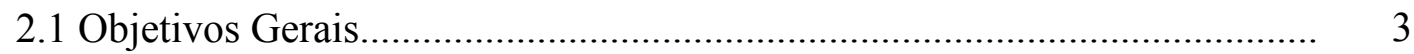

2.2 Objetivos Específicos........................................................................... 3

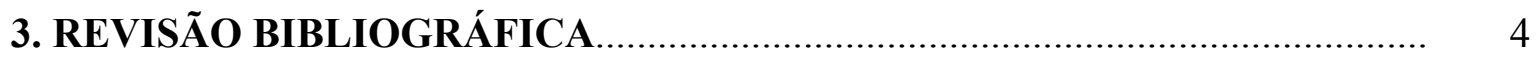

3.1 Introdução............................................................................................ 4

3.2 Contextualização.............................................................................. 5

3.3 O Sistema de ligação com CDE's........................................................... 8

3.3.1 Generalidades do Sistema................................................................ 8

3.3.2 Algumas informações sobre o conector metálico................................ 11

3.3.3 Panorama internacional............................................................. 12

3.4 Normas Internacionais.................................................................. 17

3.4.1 Os Métodos de Ensaio..................................................................... 17 
3.4.2 Os Critérios de Dimensionamento

3.5 NBR 7190/1997 - Projetos de Estruturas de Madeira................................ 22

3.6 Conclusões sobre a Revisão Bibliográfica.................................................. 26

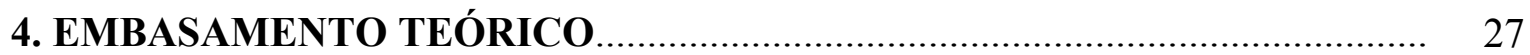

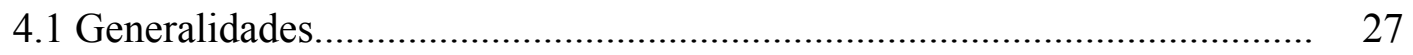

4.2 Modelo Matemático................................................................................ 28

4.3 Outras Considerações...................................................................... $\quad 30$

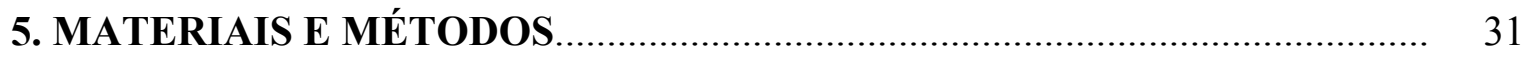

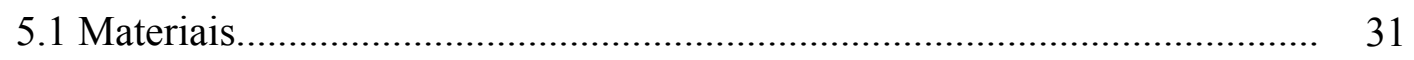

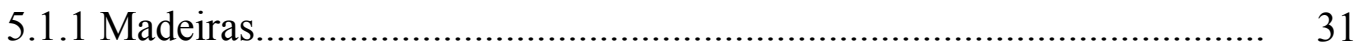

5.1.1.1 Dicotiledôneas..................................................................... 31

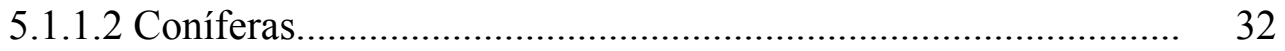

5.1.2 Conectores Metálicos...................................................................... 33

5.2 Procedimentos de Experimentação............................................................. 33

5.2.1 Ensaios de Compressão Paralela........................................................ 33

5.2.2 Ensaios de Embutimento................................................................. 35

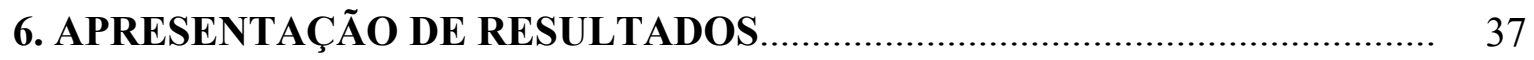

6.1 Ensaios de Compressão Paralela às Fibras................................................. 37

6.2 Ensaios de Tração em Corpos-de-prova de Ligações..................................... 40

6.2.1 Chapas orientadas paralelamente à direção das fibras........................... 40

6.2.1 Chapas orientadas perpendicularmente à direção das fibras.................. 43

6.3 Ensaios de Embutimento....................................................................... 46

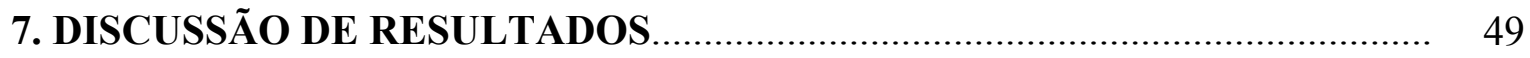

7.1 Chapas orientadas paralelamente às fibras............................................ 49 
7.1.1 Embutimento - Resistência Última............................................... 49

7.1.2 Embutimento - NBR 7190/97 .................................................... 52

7.1.3 Avaliação Estatística........................................................................... 55

7.2 Chapas orientadas perpendicularmente às fibras................................. 57

7.2.1 Embutimento - Resistência Última................................................ 57

7.2.2 Embutimento - NBR 7190/97 ................................................... 60

7.2.3 Avaliação Estatística...................................................................... 63

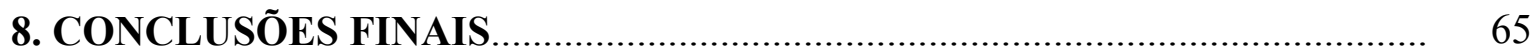

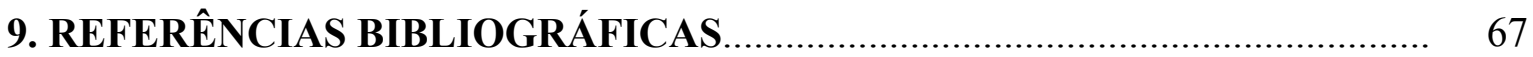

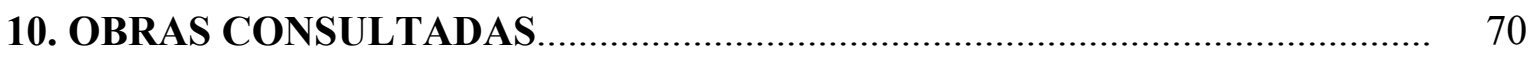




\section{LISTA DE FIGURAS}

FIGURA 01 - Estrutura de cobertura executada com CDE's como elemento de união nas ligações.

FIGURA 02 - Exemplo de um CDE.

FIGURA 03 - Esquema de prensagem de um CDE

FIGURA 04 - Equações para o cálculo da resistência ao arrancamento do CDE em função do peso específico.

FIGURA 05 - Variação dos valores do módulo de fundação em função do peso específico, umidade e ângulo em relação às fibras

FIGURA 06 - Modos de falha obtidos frente aos diferentes tipos de carregamento aplicados.

FIGURA 07 - Curva mostrando o comportamento das ligações por CDE anterior ao carregamento dinâmico

FIGURA 08 - Curva mostrando o comportamento das ligações por CDE após a aplicação do carregamento dinâmico.

FIGURA 09 - Variação das máximas resistências obtidas em função do tipo de carregamento aplicado

FIGURA 10 - Arranjo para o ensaio de tração da chapa.

FIGURA 11 - Arranjo para o ensaio de arrancamento da chapa. 
FIGURA 12 - Arranjos para o ensaio de cisalhamento da chapa

FIGURA 13 - Resistência e Rigidez de uma ligação por CDE

FIGURA 14 - Diagrama com os ciclos de carregamento

FIGURA 15 - Arranjo para os ensaios de tração ou compressão paralela às fibras.

FIGURA 16 - Arranjo para os ensaios de tração ou compressão normal às fibras e cisalhamento

FIGURA 17 - Esquema de uma ligação tracionada com CDE

FIGURA 18 - Classes de Resistência das Coníferas segundo a NBR 7190/97.....

FIGURA 19 - Classes de Resistência das Dicotiledôneas segundo a NBR 7190/97.....

FIGURA 20 - Modelo de ensaio para a avaliação da compressão paralela às fibras em um corpo-de-prova prismático de $5 \times 5 \times 15 \mathrm{~cm}$

FIGURA 21 - Modelo de ensaio para a avaliação da compressão paralela às fibras em um corpo-de-prova prismático de $5 \times 5 \times 15 \mathrm{~cm}$

FIGURA 22 - Máquina Universal de Ensaios.

FIGURA 23 - Esquema de um corpo-de-prova para a realização do ensaio de embutimento segundo a NBR 7190/97.

FIGURA 25 - Modelo de um corpo-de-prova de embutimento utilizado nos ensaios.

FIGURA 26 - Montagem utilizada nos ensaios de embutimento na máquina de ensaios DARTEC - 10KN 


\section{LISTA DE TABELAS}

TABELA 01 - Classificação das Espécies estudadas conforme preconizado pela NBR7190/97 após ensaios de Compressão Paralela (Coníferas)

TABELA 02 - Classificação das Espécies estudadas conforme preconizado pela NBR7190/97 após ensaios de Compressão Paralela (Dicotiledôneas)..

TABELA 03 - Valores de resistência à compressão paralela às fibras: Peroba Rosa....

TABELA 04 - Valores de resistência à compressão paralela às fibras: Eucalipto Grandis

TABELA 05 - Valores de resistência à compressão paralela às fibras: Cambará..........

TABELA 06 - Valores de resistência à compressão paralela às fibras: Cedrilho

TABELA 07 - Valores de resistência à compressão paralela às fibras: Pinus Elliottii.. 38

TABELA 08 - Valores de resistência à compressão paralela às fibras: Pinus Caribaea

TABELA 09 - Valores de resistência à compressão paralela às fibras: Pinus Taeda....

TABELA 10 - Valores de resistência última $\left(\mathrm{F}_{\mathrm{exp}}\right)$ da ligação ensaiada e valores da resistência convencional (R) dada pela NBR 7190: Peroba

TABELA 11 - Valores de resistência última $\left(\mathrm{F}_{\mathrm{exp}}\right)$ da ligação ensaiada e valores da resistência convencional (R) dada pela NBR 7190: Eucalipto Grandis.

TABELA 12 - Valores de resistência última $\left(\mathrm{F}_{\exp }\right)$ da ligação ensaiada e valores da resistência convencional (R) dada pela NBR 7190: Cambará. 
TABELA 13 - Valores de resistência última $\left(\mathrm{F}_{\text {exp }}\right)$ da ligação ensaiada e valores da resistência convencional (R) dada pela NBR 7190: Cedrilho.

TABELA 14 - Valores de resistência última $\left(\mathrm{F}_{\exp }\right)$ da ligação ensaiada e valores da resistência convencional (R) dada pela NBR 7190: Pinus Elliottii.......

TABELA 15 - Valores de resistência última $\left(F_{\exp }\right)$ da ligação ensaiada e valores da resistência convencional (R) dada pela NBR 7190: Pinus Caribaea.....

TABELA 16 - Valores de resistência última $\left(\mathrm{F}_{\mathrm{exp}}\right)$ da ligação ensaiada e valores da resistência convencional (R) dada pela NBR 7190: Pinus Taeda..........

TABELA 17 - Valores de resistência última $\left(\mathrm{F}_{\mathrm{exp}}\right)$ da ligação ensaiada e valores da resistência convencional (R) dada pela NBR 7190: Peroba

TABELA 18 - Valores de resistência última $\left(\mathrm{F}_{\exp }\right)$ da ligação ensaiada e valores da resistência convencional (R) dada pela NBR 7190: Eucalipto Grandis.

TABELA 19 - Valores de resistência última $\left(\mathrm{F}_{\exp }\right)$ da ligação ensaiada e valores da resistência convencional (R) dada pela NBR 7190: Cambará

TABELA 20 - Valores de resistência última $\left(\mathrm{F}_{\exp }\right)$ da ligação ensaiada e valores da resistência convencional (R) dada pela NBR 7190: Cedrilho.

TABELA 21 - Valores de resistência última $\left(\mathrm{F}_{\mathrm{exp}}\right)$ da ligação ensaiada e valores da resistência convencional (R) dada pela NBR 7190: Pinus Elliottii.......

TABELA 22 - Valores de resistência última $\left(\mathrm{F}_{\exp }\right)$ da ligação ensaiada e valores da resistência convencional (R) dada pela NBR 7190: Pinus Caribaea.....

TABELA 23 - Valores de resistência última $\left(\mathrm{F}_{\mathrm{exp}}\right)$ da ligação ensaiada e valores da resistência convencional (R) dada pela NBR 7190: Pinus Taeda..........

TABELA 24 - Valores da resistência última ao embutimento paralelo às fibras $\left(\mathrm{E}_{0}\right)$ e da resistência ao embutimento paralelo $\left(\mathrm{f}_{\mathrm{emb}, 0}\right)$ calculada segundo as recomendações da NBR 7190/97: Peroba Rosa 
TABELA 25 - Valores da resistência última ao embutimento paralelo às fibras $\left(E_{0}\right)$ e da resistência ao embutimento paralelo $\left(f_{\text {emb, }, 0}\right)$ calculada segundo as recomendações da NBR 7190/97: Eucalipto Grandis.

TABELA 26 - Valores da resistência última ao embutimento paralelo às fibras $\left(E_{0}\right)$ e da resistência ao embutimento paralelo $\left(f_{\mathrm{emb}, 0}\right)$ calculada segundo as recomendações da NBR 7190/97: Cambará

TABELA 27 - Valores da resistência última ao embutimento paralelo às fibras $\left(E_{0}\right)$ e da resistência ao embutimento paralelo $\left(f_{\mathrm{emb}, 0}\right)$ calculada segundo as recomendações da NBR 7190/97: Cedrilho.

TABELA 28 - Valores da resistência última ao embutimento paralelo às fibras $\left(E_{0}\right)$ e da resistência ao embutimento paralelo $\left(\mathrm{f}_{\mathrm{emb}, 0}\right)$ calculada segundo as recomendações da NBR 7190/97: Pinus Elliottii.

TABELA 29 - Valores da resistência última ao embutimento paralelo às fibras $\left(\mathrm{E}_{0}\right)$ e da resistência ao embutimento paralelo $\left(f_{\text {emb, } 0}\right)$ calculada segundo as recomendações da NBR 7190/97: Pinus Caribaea...

TABELA 30 - Valores da resistência última ao embutimento paralelo às fibras $\left(E_{0}\right)$ e da resistência ao embutimento paralelo $\left(\mathrm{f}_{\mathrm{emb}, 0}\right)$ calculada segundo as recomendações da NBR 7190/97: Pinus Taeda.

TABELA 31 - Peroba Rosa a $0^{\circ}-($ Classe C60).

TABELA 32 - Eucalipto Grandis a $0^{\circ}-($ Classe C40)...

TABELA 33 - Cambará a $0^{\circ}$ - (Classe C30).

TABELA 34 - Cedrilho a $0^{\circ}-($ Classe C20) 50

TABELA 35 - Pinus Elliottii a $0^{\circ}$ - (Classe C30)... 50

TABELA 36 - Pinus Caribaea a $0^{\circ}$ - (Classe C25).

TABELA 37 - Pinus Taeda a $0^{\circ}$ - (Classe C20). 
TABELA 38 - Peroba Rosa a $0^{\circ}$ - (Classe C60)

TABELA 39 - Eucalipto Grandis a $0^{\circ}$ - (Classe C40).............................................. 52

TABELA 40 - Cambará a $0^{\circ}$ - (Classe C30).............................................................. 53

TABELA 41 - Cedrilho a $0^{\circ}$ - (Classe C20)............................................................ 53

TABELA 42 - Pinus Elliottii a $0^{\circ}$ - (Classe C30).................................................... 53

TABELA 43 - Pinus Caribaea a $0^{\circ}$ - (Classe C25)................................................. 53

TABELA 44 - Pinus Taeda a $0^{\circ}$ - (Classe C20)....................................................... 54

TABELA 45 - Avaliação Estatística para os resultados obtidos a partir do Embutimento Último

TABELA 46 - Avaliação Estatística para os resultados obtidos a partir do Embutimento segundo a NBR 7190/97.............................................. 55

TABELA 47 - Peroba Rosa a 90 - (Classe C60)..................................................... 57

TABELA 48 - Eucalipto Grandis a $90^{\circ}$ - (Classe C40).......................................... 57

TABELA 49 - Cambará a 90 - (Classe C30)........................................................... 58

TABELA 50 - Cedrilho a $90^{\circ}$ - (Classe C20) ............................................................ 58

TABELA 51 - Pinus Elliottii a 90º $-($ Classe C30)................................................... 58

TABELA 52 - Pinus Caribaea a $90^{\circ}$ - (Classe C25)................................................ 58

TABELA 53 - Pinus Taeda a $90^{\circ}$ - (Classe C20)..................................................... 59

TABELA 54 - Peroba Rosa a 90 - (Classe C60)........................................................ 60

TABELA 55 - Eucalipto Grandis a $90^{\circ}$ - (Classe C40)............................................. 60

TABELA 56 - Cambará a 90 - (Classe C30)............................................................ 61 
TABELA 57 - Cedrilho a 90 $-($ Classe C20) ....................................................... 61

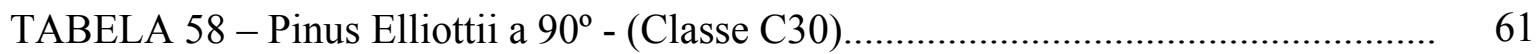

TABELA 59 - Pinus Caribaea a $90^{\circ}$ - $($ Classe C25) ................................................... 61

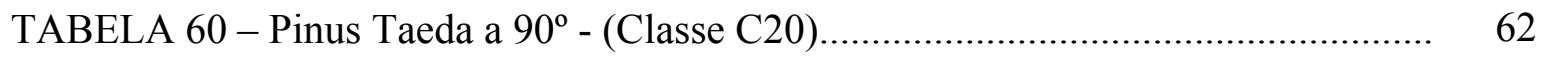

TABELA 61 - Avaliação Estatística para os resultados obtidos a partir do Embutimento Último..................................................................... 63

TABELA 62 - Avaliação Estatística para os resultados obtidos a partir do Embutimento segundo a NBR 7190/97........................................... 63 


\section{LISTA DE ABREVIATURAS E SIGLAS}

$\begin{array}{llll}\text { ABNT } & - & \text { Associação Brasileira de Normas Técnicas } \\ \text { ANSI } & - & \text { American National Standards Institute } \\ \text { ASTM } & - & \text { American Society for Testing and Materials } \\ \text { BS } & - & \text { British Standards } \\ \text { CDE } & - & \text { Chapas com Dentes Estampados } \\ \text { CSA } & - & \text { Canadian Standards Association } \\ \text { EESC } & - & \text { Escola de Engenharia de São Carlos } \\ \text { IBGE } & - & \text { Instituto Brasileiro de Geografia } \\ \text { LaMEM } & - & \text { Laboratório de Madeiras e Estruturas de Madeira } \\ \text { NBR } & - & \text { Norma Brasileira Registrada } \\ \text { NCH } & - & \text { Norma Chilena } \\ \text { SET } & - & \text { Departamento de Engenharia de Estruturas } \\ \text { TPI } & - & \text { Truss Plate Institute } \\ \text { USP } & - & \text { Universidade de São Paulo }\end{array}$




\title{
LISTA DE SÍMBOLOS
}

\author{
A................ Área de Seção Transversal \\ $\mathrm{E}_{\mathrm{c} 0 \ldots \ldots \ldots} \ldots$ Módulo de Elasticidade à compressão paralela às fibras \\ $\mathrm{E}_{\mathrm{c} 0, \mathrm{~m}}$......... Valor médio do Módulo de Elasticidade à compressão paralela às \\ fibras \\ F.......... Força concentrada aplicada \\ $\mathrm{f}_{\mathrm{c} 0 \mathrm{k}} \ldots \ldots \ldots$ Resistência característica à compressão paralela às fibras

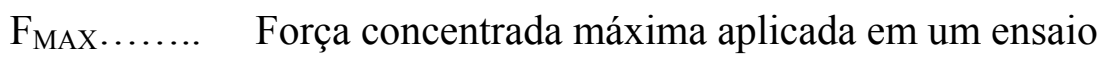 \\ $\mathrm{f}_{\mathrm{vk}} \ldots \ldots \ldots \ldots$ Resistência característica ao cisalhamento \\ K.......... Coeficiente de rigidez da ligação
}




\section{RESUMO}

O crescimento da população urbana, bem como as diferenças sociais brasileiras, têm causado significativa degradação nas condições de vida e de moradia em nosso país. Tal fato vem reforçar a necessidade de se intensificar as pesquisas que tenham como objetivos a produção de alternativas tecnológicas para solucionar-se tais problemas. Não é ainda comum no Brasil o uso de chapas com dentes estampados para se fazer a conexão de peças estruturais de madeira, apesar dessas se apresentarem como uma ótima alternativa estrutural e econômica para tal. A norma brasileira, NBR 7190/97 Projeto de Estruturas de Madeira, não apresenta um método com os critérios de dimensionamento para tais tipos de ligação. Baseado em estudos teóricos e experimentais desenvolvidos no Laboratório de Madeira e de Estruturas de Madeira (LaMEM), do departamento de Engenharia de Estruturas da Escola de Engenharia de São Carlos, Universidade de São Paulo, são apresentados neste trabalho contribuições para o desenvolvimento de tais critérios para o dimensionamento destas ligações. O presente estudo foi desenvolvido para atender as especificações de espécies tropicais nativas e de reflorestamento encontradas em território nacional.

Palavras-Chave: ligações; chapas com dentes estampados; conector metálico. 


\begin{abstract}
The increase number of urban population such as the social disparity of Brazilian people has caused significant degradation in habitation life style, increased slum numbers and the number of homeless people. Such fact strengthen the necessity of intensify researches that produce technological alternatives to solve this problems. In Brazil, it is not common see metal plate connectors in roof trusses, in spite of this connectors been a good structural and economical alternative to execute this joints. In Brazilian code, NBR 7190/97 - Timber Structures Design, design criteria for this kind of joints are not yet established. Based on theoretical and experimental studies, carried out in Wood and Timber Structures Laboratory, Structural Engineering Department, São Carlos Engineering School, São Paulo University, in this paper such criteria design will be presented. The study was developed and calibrated to attend the specifications of native specimens of Brazilian tropical wood species.
\end{abstract}

Keywords: metal plate connectors; designs criteria; timber structures joints. 


\section{INTRODUÇÃO}

O crescimento da população urbana brasileira associado às dificuldades ainda experimentadas pelo país para alcançar uma distribuição de renda mais eqüitativa tem provocado significativa degradação nas condições de vida de milhões de brasileiros, trazendo, entre outras conseqüências, um aumento do número de favelas e outros tipos de moradia em condições subumanas, sobretudo nos grandes centros urbanos, bem como a escassez de oferta de infra-estrutura pública como hospitais, creches, estabelecimentos escolares, entre outros. Este fato ressalta a necessidade do envolvimento acadêmico na busca de soluções tecnológicas que contribuam para reverter a mencionada situação.

Os processos convencionais têm, cada vez mais, se mostrado pouco eficientes para resolver a problemática da demanda pelos diferentes tipos de edificações urbanas e rurais. Diante deste fato, os processos construtivos industrializados conseguem ganhar espaço e vêm se mostrando altamente interessantes para solucionar os problemas supracitados, em particular considerando a relação custo-benefício. Além disto, é possível atender-se à demanda de maneira mais rápida, com garantia de qualidade, em função do controle tecnológico inserido no processo, otimizando custos e com a racionalização do emprego de materiais e mão-de-obra.

Internacionalmente, muitos países experimentam o predomínio da industrialização da construção e seus documentos normativos têm incorporado as inovações tecnológicas advindas de seus centros de pesquisa e do desenvolvimento advindo dos canteiros de obra.

Tratando especificamente da pré-fabricação de estruturas de madeira, países da América do Norte e da Europa possuem uma tecnologia tal que não mais se concebe 
a construção de modo artesanal, tanto em função dos custos envolvidos, quanto da garantia da qualidade e dos prazos de entrega das obras.

Entretanto, no Brasil, ainda não foi alcançada situação semelhante. SOUZA (1995) afirma que não mais que 5\% das estruturas de cobertura, executadas em nosso país, utilizam a pré-fabricação. Neste caso, a ligação entre as barras das estruturas é executada por meio de conectores metálicos, comumente chamados de CDE's (chapas com dentes estampados).

Em países como os Estados Unidos, dado o amplo emprego das estruturas préfabricadas, ganham destaque órgãos como o Truss Plate Institute (TPI), que é responsável, entre outros aspectos, por estudos visando a otimização do emprego destes conectores metálicos, incluindo recomendações de caráter normativo para o projeto e execução das referidas estruturas.

No Brasil, a NBR 7190/97: Projeto de Estruturas de Madeira, da Associação Brasileira de Normas Técnicas (ABNT), documento normativo de nível equivalente às principais normas internacionais, ainda não apresenta critérios conclusivos para o adequado dimensionamento das ligações por CDE's. Esta circunstância se constitui numa componente restritiva à efetiva disseminação desta tecnologia no contexto brasileiro das estruturas de madeira. 


\section{OBJETIVOS}

\subsection{Objetivos Gerais}

O presente trabalho tem como objetivos gerais fornecer subsídios tecnológicos aos profissionais ligados ao projeto e à construção de estruturas de madeira, visando a difusão dos processos construtivos industrializados em nosso país, na busca pela garantia da qualidade da estrutura, num contexto de alta competitividade.

\subsection{Objetivos Específicos}

Diante das necessidades tecnológicas anteriormente apontadas, no presente trabalho objetiva-se, a partir de avaliações teóricas e experimentais, contribuir para o estabelecimento de critérios para o dimensionamento das ligações entre peças estruturais de madeira por meio de conectores metálicos com dentes estampados.

$\mathrm{Na}$ busca pela generalização dos resultados obtidos, estão sendo considerados os ensaios com diferentes espécies de madeira, sejam nativas ou de florestas artificiais, abrangendo as várias classes de resistência previstas na NBR 7190/1997. 


\section{REVISÃO BIBLIOGRÁFICA}

\subsection{Introdução}

O crescimento demográfico brasileiro com a conseqüente concentração populacional nos centros urbanos, a evolução experimentada no âmbito do projeto e da construção de benfeitorias na área rural, a diversificação do parque industrial brasileiro, são fatores que têm feito emergir a constatação da ausência de mecanismos políticos e tecnológicos adequados para o atendimento da larga demanda por soluções de tal problemática.

No que concerne aos aspectos tecnológicos, há muito se tem observado que os processos construtivos convencionais não são eficientes para a solução dos problemas acima citados, devendo ser fortemente consideradas as alternativas da préfabricação e da industrialização como mais promissoras para atender às necessidades atuais e futuras.

A indústria da construção civil e os produtores de materiais de construção vêm buscando encurtar distâncias entre as expectativas e a realidade, com o intuito de promover o desejado desenvolvimento tecnológico de modo equilibrado e racional.

Ao mesmo tempo, os documentos normativos mais recentes têm incorporado avanços em diversas áreas do conhecimento, fazendo com que velhas barreiras sejam gradativamente transpostas e novas tecnologias sejam, então, disseminadas, contribuindo para que o país, cada vez mais, acompanhe a evolução tecnológica já atingida em outras partes do mundo. 
Entretanto, em alguns segmentos, como é o caso da pré-fabricação e da industrialização de componentes em madeira para a construção, há ainda muito a ser feito, muitos desafios a serem vencidos. São evidentes as deficiências na transferência de informações tecnológicas sobre as numerosas espécies nativas e de reflorestamento disponíveis no país, desde as propriedades de resistência e de elasticidade, até os critérios para seu adequado dimensionamento em algumas situações em serviço, passando pelos procedimentos de usinagem, preservação e aplicação mais usuais. A ausência de providências para vencer estas limitações pode fazer com que a madeira deixe de ser considerada a excelente solução construtiva em que realmente se constitui, não por outra razão senão pela falta de conhecimento dos usuários efetivos ou potenciais.

O presente trabalho, intitulado Critérios para o dimensionamento da ligação entre peças estruturais de madeira através de chapas metálicas com dentes estampados (CDE), está inserido neste contexto. É buscada aqui a geração de subsídios para o desenvolvimento racional de projetos que mantenham a competitividade da madeira como material estrutural.

\subsection{Contextualização}

Desde o surgimento das chapas metálicas com dentes estampados (CDE's), detalhadas no item 3.3.1 do presente trabalho, diversas pesquisas vêm sendo desenvolvidas no tocante a este sistema. Entretanto, em nosso país, tal estudo tem experimentado importância apenas a partir do final da década de 80 do século passado. Mesmo assim, poucas informações consistentes são encontradas a respeito do assunto na literatura técnica nacional.

De acordo com ALMEIDA (1997), por se tratar de um sistema de ligações consideravelmente recente, em nível nacional, são poucas as informações experimentais sobre o comportamento das ligações de peças de madeiras nativas brasileiras fixadas com CDE's. 
Já em outros países, o estudo e a aplicação de conectores metálicos vêm sendo amplamente difundidos, como pode ser observado através do trabalho de STERN (1992), no qual é apresentado um relato dos principais trabalhos desenvolvidos sobre o tema a partir da década de 60. Através deste artigo, pode-se observar que, desde a década de 70, o sistema de ligações por CDE's já era tema de discussão internacional, em função de seu potencial altamente interessante no que diz respeito à pré-fabricação de estruturas de madeira.

$\mathrm{O}$ assunto começou a ganhar força em nosso país a partir do agravamento do problema de moradia, em particular nos anos 80 , que tendia a um significativo agravamento. Como dado estatístico, de acordo com os recenseamentos feitos no período de 1940 a 1980, acusa-se o crescimento da população brasileira de 40 para 120 milhões de habitantes, com o agravante da população urbana de 1940 ser de 13 milhões ( $31 \%$ da população total), enquanto, em 1980, era de 80 milhões ( $76 \%$ da população total), BARROS (1991).

De acordo com o último censo demográfico realizado no ano de 2000 pelo IBGE, a população brasileira atinge 169.590 .693 habitantes. Deste número, 137.755 .550 são residentes em zona urbana, o que corresponde a uma parcela de $81,23 \%$ da população total brasileira. Isto significa que, nos últimos vinte anos, o crescimento da população urbana foi de $72 \%$.

BARROS (1991) afirma, ainda, que a indústria da construção civil no ramo das estruturas de madeira não vinha sendo objeto de atenção em nosso país, dada a predominância do modo artesanal como tais estruturas são produzidas, situação esta gerada em função do reduzido número de profissionais, engenheiros civis, especializados no assunto e conscientes do potencial e das possibilidades que a madeira pode proporcionar à construção civil, bem como da redução do número de oficiais carpinteiros capacitados para a execução de obras.

Pensando especificamente a respeito de conectores metálicos, um dos primeiros trabalhos nacionais sobre o assunto é o de BREUER (1983), no qual são apresentados dados históricos e práticos a respeito do emprego de CDE's. 
Podem ser citados, também, os trabalhos publicados por UJVARI (1983) que traz algumas informações introdutórias a respeito de valores estimativos da resistência das ligações por CDE's, baseados ainda em conceitos do Método das Tensões Admissíveis, para projetos de estruturas de madeira, cujos conceitos vigoravam na época; e por OLIVEIRA (1988) que faz algumas avaliações sobre o comportamento da ligação por CDE's em espécies nativas com diferentes densidades aparentes, variando as dimensões das chapas utilizadas.

A partir de então, poucos trabalhos nacionais a respeito do assunto foram apresentados. Merece especial destaque a dissertação de BARALDI (1996) em que foram definidos os métodos de ensaio para ligações de estruturas de madeira por chapas com dentes estampados e que serão apresentados detalhadamente mais adiante no decorrer deste texto.

Vale a pena citar que, neste mesmo trabalho, BARALDI (1996) deixa clara a importância e recomenda a realização de um estudo como o aqui proposto, não só pela inexistência de critérios de dimensionamento propriamente ditos, mas pela necessidade de se adequar o uso destes conectores à realidade das madeiras brasileiras, uma vez que é de conhecimento geral que o Brasil, favorecido por seu clima tropical, possui madeiras nativas com características de resistência muito diversificadas, em geral superiores às de grande número de espécies de uso consagrado internacionalmente, e espécies de reflorestamento com desempenho altamente satisfatório..

O trabalho nacional mais recente a respeito do tema em questão foi apresentado por SERAPHIM E FRANCO (2001), no qual se estudou o comportamento da resistência e da rigidez de ligações tracionadas, unidas por chapas com dentes estampados, em função do aumento da espessura das peças de madeira solidarizadas. Para tal, foram utilizadas peças com densidade aparente equivalente e conectores metálicos de mesmas dimensões nominais.

Os referidos autores concluíram, pelos resultados obtidos, que existe uma tendência de redução da resistência e da rigidez destas ligações quando se aumenta a espessura das peças interligadas, frente às condições já descritas. Evidenciaram também, em 
seu trabalho, a necessidade de se determinar as causas envolvidas no fenômeno e de se estabelecer critérios de dimensionamento, levando em conta a espessura das peças a solidarizar e da chapa metálica utilizada. Com isto será possível otimizar o dimensionamento das citadas ligações, compatibilizando custo e garantindo a competitividade das estruturas de madeira.

\subsection{O Sistema de ligação por CDE's}

\subsubsection{Generalidades do Sistema}

Um dos grandes responsáveis pelo desenvolvimento internacional da indústria das estruturas de madeira tem sido o emprego das chapas metálicas com dentes estampados (CDE) na produção de estruturas treliçadas para cobertura.

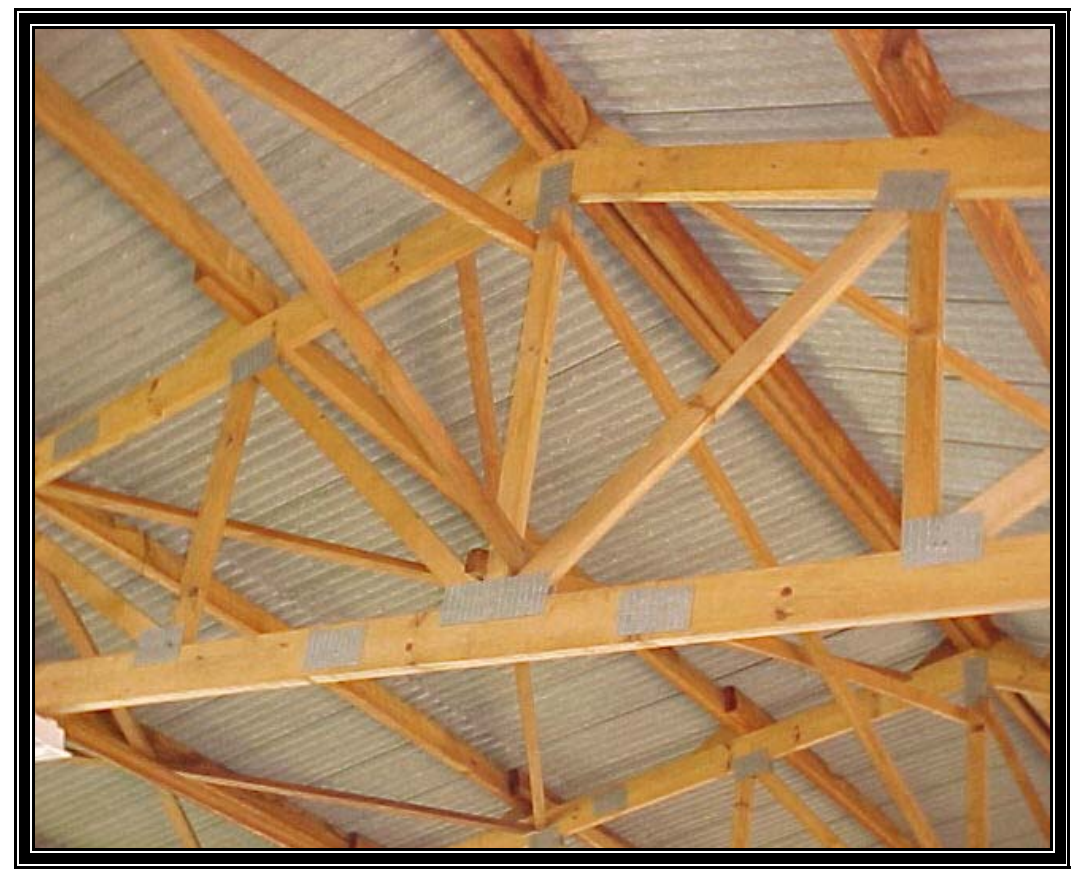

Figura 01 - Estrutura de cobertura executada com CDE's como elemento de união nas ligações 
Tal sistema foi originalmente desenvolvido em 1955 nos Estados Unidos por J. Calvin Jureit (Gang-Nail, 1975), e é composto por ligações e fixações de elementos de madeira através de cobrejuntas metálicas, projetadas para maximizar sua resistência em função das condições de trabalho (tração, compressão, flexão e cisalhamento). A inovação recebeu o nome de sistema Gang-Nail e a empresa Automated Building Components, Inc. passou a fabricar e distribuir esses conectores, inicialmente nos Estados Unidos e, em seguida, para países como o Brasil, boa parte da América Latina, Europa e África, sendo a sua primeira patente outorgada em 1959, BARROS (1992).

Esses conectores foram concebidos como alternativa econômica para a confecção de ligações e, consequentemente, de coberturas mais leves com madeira de espécies menos nobres, aplicando-se conceituação diferente de projeto e de construção, utilizando-se peças de menores dimensões, promovendo uma melhor distribuição de cargas e, finalmente, um alívio das tensões atuantes nessas peças, gerando economia de madeira, maior eficiência de montagem e melhor controle de qualidade nas obras.

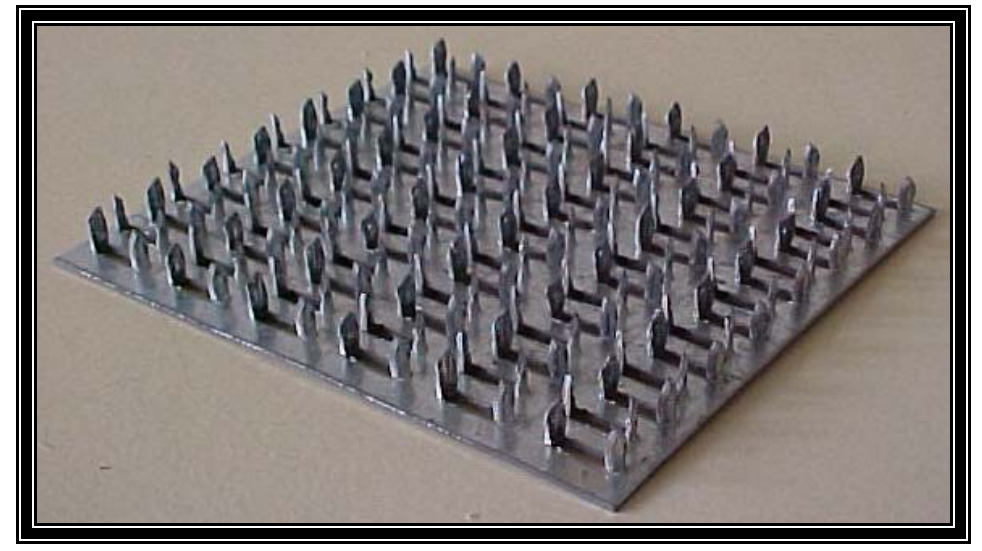

Figura 02 - Exemplo de um CDE

Essas "chapas-prego", como são usualmente chamadas, têm menor espessura e maior resistência, solucionam inconvenientes tais como a exigência de pregos ou parafusos de diâmetro e peso elevados, evitam rachaduras na madeira, a diminuição da área útil 
da seção transversal das peças, trazendo ainda como vantagem a possibilidade de se ligar peças menores.

Inicialmente, nessas talas metálicas, os pregos eram colocados um a um, em trabalho mais demorado e artesanal. Na continuação, surgiu a chapa com pregos já estampados segundo ângulos retos em relação a seu plano. O processo de ligação consiste basicamente em se colocar as peças a serem ligadas, em posicionar as chapas e proceder à respectiva prensagem. Isto possibilita a produção em larga escala, contribuindo para justificar a idéia da industrialização das estruturas de madeira.

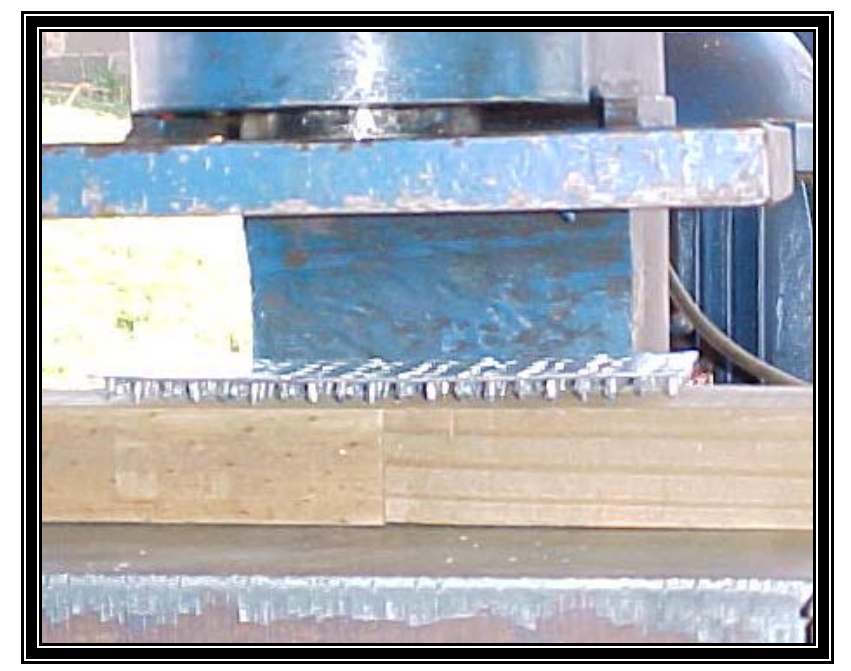

Figura 03 - Esquema de prensagem do CDE

No que se refere ao Brasil, é oportuno lembrar que, segundo SOUZA (1995), em torno de $75 \%$ das construções têm suas estruturas de cobertura executadas em madeira, mas menos de 5\% empregam ligações com $\mathrm{CDE}$, o que ilustra a relevância do presente estudo. Isto ocorre em função de alguns fatores como a falta de conhecimento técnico dos profissionais da área a respeito do assunto, como já mencionado anteriormente e a falta de subsídios do documento normativo que não apresenta critérios conclusivos para o dimensionamento de tais ligações. 


\subsubsection{Algumas informações sobre o conector metálico}

Os conectores metálicos utilizados no presente trabalho são fabricados com aço galvanizado a quente de primeira qualidade e contém as seguintes especificações dadas pelo fabricante:

$\checkmark$ Atendimento aos requisitos da ASTM A446-72 Grau A;

$\checkmark$ Tensão admissível à tração de $14 \mathrm{KN} / \mathrm{cm}^{2}$;

$\checkmark$ Cisalhamento admissível de $9,8 \mathrm{KN} / \mathrm{cm}^{2}$;

$\checkmark$ Limite de escoamento de $23,2 \mathrm{KN} / \mathrm{cm}^{2}$;

$\checkmark$ Limite de resistência à tração de $31,64 \mathrm{KN} / \mathrm{cm}^{2}$;

Constam ainda, a seguir, algumas informações fornecidas pelos fabricantes e que serão utilizados nos cálculos do presente trabalho:

$\checkmark$ Número de dentes de 1,5 dentes $/ \mathrm{cm}^{2}$;

$\checkmark$ Espessura de 1,23mm (chegando até 1,38mm);

$\checkmark$ Comprimento dos dentes de 7,8mm;

$\checkmark$ Quantidade efetiva de aço que resiste às solicitações longitudinais: $32,7 \%$;

$\checkmark$ Quantidade efetiva de aço que resiste às solicitações transversais: $70,2 \%$;

$\checkmark$ Peso específico de um CDE: $1,05 \mathrm{~g} / \mathrm{cm}^{2}$ 


\subsubsection{Panorama internacional}

Internacionalmente, em países como Estados Unidos, Canadá, países europeus, o sistema de ligação por CDE's em estruturas de madeira já está bem definido e embasado no que concerne aos métodos e critérios para o dimensionamento destas.

Os estudos realizados atualmente nesses países se concentram em estudos específicos de casos; vão também, no sentido de otimizar o processo, descobrir novos meios que melhorem e acelerem o processo de fabricação das estruturas de madeira com ligações por CDE's.

VIA, ZINK-SHARP, WOESTE, DOLAN (1999), por exemplo, estudaram a relação entre a resistência dos dentes dos conectores e o peso específico da madeira Southern Pine com a finalidade de estabelecer um método de avaliação da madeira serrada da referida espécie para estimar a capacidade de resistência do conector a partir do peso específico da madeira sem que para tal seja necessária a realização de outros tipos de ensaio além daquele para a determinação do peso específico. Tal estudo deve-se ao fato do Southern Pine ser uma espécie muito "popular" e utilizada em larga escala na produção de estruturas de cobertura com ligações através de chapas com dentes estampados. Tendo analisado quatro diferentes tipos de configuração para as ligações com CDE's, os autores determinaram as seguintes expressões, conforme mostrado na figura 4 a seguir, que podem ser utilizadas para estimar a resistência ao arrancamento do conector da ligação em função da densidade da mencionada espécie.

\begin{tabular}{ccccc}
\hline $\begin{array}{c}\text { Orientação das fibras com a } \\
\text { placa }\end{array}$ & \multicolumn{1}{c}{$\begin{array}{c}\text { Equação obtida para o cálculo da carga } \\
\text { máxima permitida }\end{array}$} & $r^{2}$ & $\begin{array}{c}\text { Peso Específico } \\
\text { (PE) }\end{array}$ & PE $^{2}$ \\
\hline LRAA & $\mathrm{U}_{\text {LRAA }}=430(\mathrm{SG})+361$ & 0,578 & 0,0001 & $* * * * *$ \\
LREA & $\mathrm{U}_{\text {LREA }}=991(\mathrm{SG})-662(\mathrm{SG})^{2}+147$ & 0,834 & 0,0076 & 0,0431 \\
LRAE & $\mathrm{U}_{\text {LRAE }}=326(\mathrm{SG})+239$ & 0,391 & 0,0004 & $* * * * *$ \\
LREE & $\mathrm{U}_{\text {LREE }}=737(\mathrm{SG})+86,9$ & 0,606 & 0,0001 & $* * * * *$ \\
\hline
\end{tabular}

Figura 04 - Equações para o cálculo da resistência ao arrancamento do CDE em função do peso específico [Fonte: VIA et al (1999)]. 
As orientações das fibras com a placa, citadas na tabela acima, constam:

LRAA: Chapa e fibras da madeira paralelas ao carregamento.

LREA: Chapa perpendicular e fibras da madeira paralelas ao carregamento.

LRAE: Chapa paralela e fibras da madeira perpendicular ao carregamento.

LREE: Chapa e fibras perpendiculares ao carregamento.

RILEY, GEBREMEDHIN (1999) propuseram um modelo empírico que, baseado na orientação das fibras, no peso específico da madeira e em seu teor de umidade, fornece o chamado módulo de fundação da ligação. Para tal, realizaram 150 testes para avaliar o comportamento das ligações nas quais foram utilizados os conectores e as espécies de madeira de densidades mais usuais na construção de telhados nos EUA. Na tabela abaixo, SG é o peso específico da madeira, MC a porcentagem de umidade e K é o modulo de fundação da ligação.

\begin{tabular}{|c|c|c|c|c|c|c|c|c|c|c|c|c|c|c|c|}
\hline $\begin{array}{c}\theta \\
\left({ }^{\circ}\right) \\
\end{array}$ & SG & $\begin{array}{l}\mathrm{MC} \\
(\%)\end{array}$ & $\begin{array}{c}\mathrm{K} \\
(\mathrm{N} / \mathrm{mm})\end{array}$ & SG & $\begin{array}{l}\mathrm{MC} \\
(\%)\end{array}$ & $\begin{array}{c}\mathrm{K} \\
(\mathrm{N} / \mathrm{mm})\end{array}$ & SG & $\begin{array}{l}\mathrm{MC} \\
(\%)\end{array}$ & $\begin{array}{c}\mathrm{K} \\
(\mathrm{N} / \mathrm{mm})\end{array}$ & SG & $\begin{array}{l}\mathrm{MC} \\
(\%)\end{array}$ & $\begin{array}{c}\mathrm{K} \\
(\mathrm{N} / \mathrm{mm})\end{array}$ & SG & $\begin{array}{l}\mathrm{MC} \\
(\%)\end{array}$ & $\begin{array}{c}\mathrm{K} \\
(\mathrm{N} / \mathrm{mm})\end{array}$ \\
\hline & 0,36 & 1 & 20,80 & 0,44 & 1 & 41,70 & 0,51 & 1 & 44,00 & 0,64 & 12 & 37,5 & 0,54 & 16 & 27,80 \\
\hline & 0,35 & 1 & 25,40 & 0,45 & 1 & 44,80 & 0,47 & 1 & 33,80 & 0,63 & 12 & 35 & 0,48 & 16 & 26,10 \\
\hline & 0,36 & 1 & 22,60 & 0,43 & 1 & 48,20 & 0,49 & 1 & 38,20 & 0,59 & 13 & 36,2 & 0,45 & 15 & 26,60 \\
\hline & 0,34 & 11 & 18,20 & 0,40 & 8 & 31,20 & 0,51 & 9 & 34,50 & 0,55 & 11 & 27,8 & 0,55 & 16 & 37,00 \\
\hline & 0,34 & 11 & 18,40 & 0,41 & 8 & 28,50 & 0,54 & 9 & 32,00 & 0,57 & 12 & 29,9 & 0,57 & 16 & 35,70 \\
\hline & 0,35 & 11 & 18,90 & 0,40 & 8 & 35,20 & 0,53 & 10 & 22,60 & 0,61 & 12 & 33,8 & 0,61 & 16 & 37,00 \\
\hline \multirow[t]{6}{*}{30} & 0,34 & 1 & 33,30 & 0,43 & 1 & 43,80 & 0,50 & 1 & 35,60 & 0,59 & 12 & 31,2 & 0,42 & 14 & 30,60 \\
\hline & 0,36 & 2 & 30,60 & 0,44 & 1 & 45,20 & 0,45 & 1 & 33,40 & 0,62 & 12 & 36,8 & 0,41 & 15 & 31,00 \\
\hline & 0,32 & 2 & 27,50 & 0,43 & 1 & 48,90 & 0,47 & 1 & 51,50 & 0,60 & 12 & 29,8 & 0,41 & 15 & 25,40 \\
\hline & 0,32 & 12 & 25,40 & 0,42 & 7 & 36,60 & 0,49 & 9 & 35,20 & 0,66 & 13 & 33,6 & 0,43 & 14 & 37,60 \\
\hline & 0,35 & 12 & 21,50 & 0,45 & 7 & 28,40 & 0,47 & 9 & 32,40 & 0,60 & 13 & 27,3 & 0,42 & 14 & 29,80 \\
\hline & 0,36 & 12 & 23,60 & 0,44 & 7 & 41,70 & 0,49 & 9 & 31,50 & 0,59 & 13 & 33,6 & 0,40 & 15 & 30,10 \\
\hline \multirow[t]{6}{*}{45} & 0,33 & 1 & 31,50 & 0,41 & 1 & 27,80 & 0,48 & 1 & 29,60 & 0,54 & 13 & 23,5 & 0,48 & 17 & 33,30 \\
\hline & 0,37 & 1 & 29,90 & 0,39 & 1 & 37,60 & 0,47 & 1 & 27,70 & 0,66 & 12 & 26,8 & 0,50 & 17 & 37,00 \\
\hline & 0,35 & 1 & 31,90 & 0,40 & 1 & 24,90 & 0,47 & 1 & 32,90 & 0,61 & 12 & 33,6 & 0,48 & 17 & 35,00 \\
\hline & 0,34 & 12 & 20,30 & 0,44 & 8 & 29,10 & 0,50 & 9 & 26,30 & 0,59 & 13 & 33,6 & 0,50 & 17 & 29,10 \\
\hline & 0,34 & 12 & 20,10 & 0,40 & 8 & 29,10 & 0,46 & 9 & 28,50 & 0,65 & 12 & 30,8 & 0,50 & 17 & 26,80 \\
\hline & 0,35 & 12 & 20,70 & 0,42 & 8 & 27,50 & 0,47 & 9 & 20,00 & 0,62 & 13 & 40,3 & 0,51 & 16 & 37,50 \\
\hline \multirow[t]{6}{*}{60} & 0,34 & 1 & 31,20 & 0,43 & 1 & 40,30 & 0,50 & 1 & 35,20 & 0,59 & 12 & 46,9 & 0,42 & 14 & 31,50 \\
\hline & 0,36 & 1 & 32,40 & 0,44 & 1 & 44,10 & 0,45 & 1 & 38,50 & 0,62 & 12 & 34 & 0,41 & 15 & 35,40 \\
\hline & 0,32 & 1 & 27,10 & 0,43 & 1 & 43,10 & 0,47 & 1 & 46,10 & 0,60 & 12 & 31,7 & 0,41 & 15 & 31,90 \\
\hline & 0,32 & 12 & 27,50 & 0,42 & 7 & 34,80 & 0,49 & 9 & 23,30 & 0,66 & 13 & 43,8 & 0,43 & 14 & 32,60 \\
\hline & 0,35 & 12 & 23,60 & 0,45 & 7 & 34,50 & 0,47 & 9 & 30,80 & 0,60 & 13 & 3534 & 0,42 & 14 & 35,00 \\
\hline & 0,36 & 12 & 23,30 & 0,44 & 7 & 31,20 & 0,49 & 9 & 47,30 & 0,59 & 13 & 43,4 & 0,40 & 15 & 29,80 \\
\hline \multirow[t]{6}{*}{90} & 0,36 & 1 & 28,20 & 0,44 & 1 & 45,50 & 0,51 & 1 & 67,80 & 0,64 & 12 & 40,3 & 0,54 & 16 & 25,70 \\
\hline & 0,35 & 1 & 23,30 & 0,45 & 1 & 35,00 & 0,47 & 1 & 64,80 & 0,63 & 12 & 38,7 & 0,48 & 16 & 33,60 \\
\hline & 0,36 & 1 & 25,70 & 0,43 & 1 & 48,00 & 0,49 & 1 & 56,70 & 0,59 & 13 & 43,2 & 0,45 & 15 & 32,00 \\
\hline & 0,34 & 12 & 30,50 & 0,40 & 8 & 48,00 & 0,51 & 9 & 37,80 & 0,55 & 11 & 29,4 & 0,55 & 16 & 54,60 \\
\hline & 0,34 & 12 & 30,60 & 0,41 & 8 & 43,20 & 0,54 & 9 & 36,20 & 0,57 & 12 & 26,4 & 0,57 & 16 & 45,20 \\
\hline & 0,35 & 12 & 27,10 & 0,40 & 8 & 40,60 & 0,53 & 10 & 27,10 & 0,61 & 12 & 34,3 & 0,61 & 16 & 25,00 \\
\hline
\end{tabular}

Figura 05 - Variação dos valores do módulo de fundação em função do peso específico, umidade e ângulo em relação às fibras [Fonte: RILEY \&

GEBREMEDHIN (1999)]. 
KENT, GUPTA, MILLER (1997) estudaram o comportamento dinâmico das ligações com CDE's quando da ocorrência de abalos sísmicos ou cargas dinâmicas cíclicas. Os resultados deste trabalho não são de grande relevância em nosso país, uma vez que o índice de abalos em território nacional é praticamente nulo. Entretanto, o estudo é interessante no sentido de comprovar a capacidade resistente e a eficiência das ligações com conectores metálicos. Após a realização dos experimentos, os autores verificaram que não houve alteração na capacidade de resistência quando feita a comparação com os resultados dos ensaios estáticos. Entretanto, foi detectado um pequeno decréscimo de rigidez, variável com a magnitude do carregamento aplicado.

Um estudo semelhante ao citado foi desenvolvido por EMERSON e FRIDLEY (1996). Estes autores estudaram o comportamento de ligações por chapas com dentes estampados frente a carregamentos dinâmicos. Foram realizados ensaios estáticos para a obtenção da resistência e da rigidez das ligações e, em seguida, realizados ensaios com aplicação de cargas dinâmicas. De modo análogo a GUPTA et al, concluíram que o comportamento da ligação com CDE's frente a carregamentos dinâmicos é semelhante ao comportamento sob carregamentos estáticos.

Os resultados obtidos por EMERSON e FRIDLEY foram sumarizados na tabela e gráficos a seguir.

\begin{tabular}{lccc}
\hline & \multicolumn{3}{c}{ Modo de Ruptura } \\
\cline { 2 - 4 } Tipo de carregamento & $\begin{array}{c}\text { Arrancamento } \\
\text { dos dentes }\end{array}$ & Cisalhamento & Tração \\
\hline Pré-dinâmico e estático & 41 & 11 & 8 \\
Pós-dinâmico e estático & 41 & 8 & 2 \\
Dinâmico & 7 & 1 & 1 \\
Total & 89 & 20 & 11 \\
\hline
\end{tabular}

Figura 06 - Modos de falha obtidos frente aos diferentes tipos de carregamento aplicados [Fonte: EMERSON \& FRIDLEY (1996)]. 
Antes

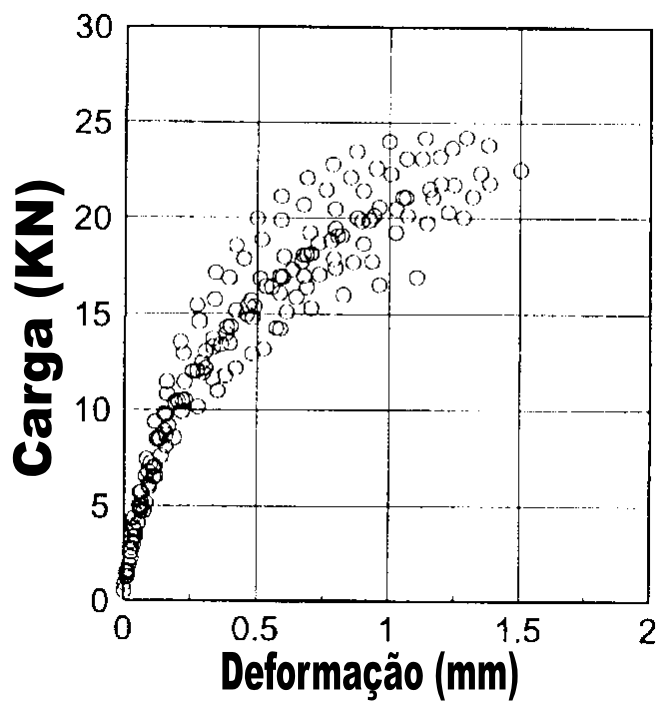

Depois

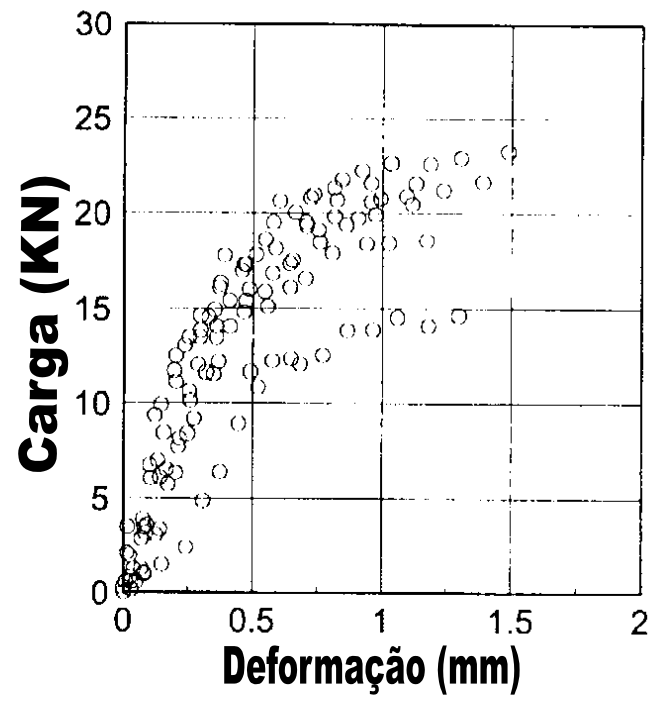

Figuras 07 e 08 - Curvas mostrando o comportamento das ligações por CDE frente ao carregamento dinâmico, antes e depois [Fonte: EMERSON \& FRIDLEY (1996)].

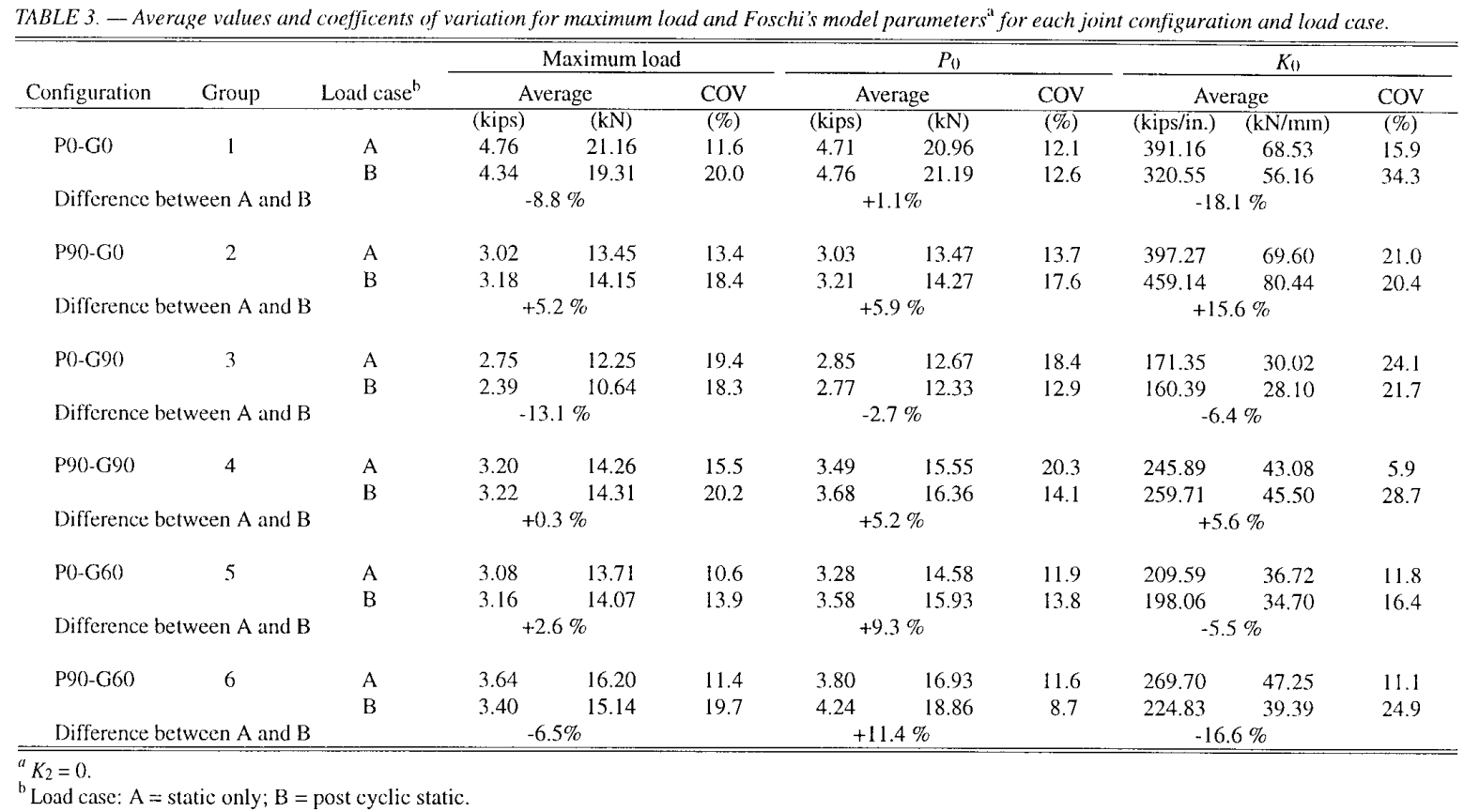

Figura 09 - Variação das máximas resistências obtidas em função do tipo de carregamento aplicado [Fonte: EMERSON \& FRIDLEY (1996)]. 
STAHL, CRAMER, WOLFE (1996) estudaram a possibilidade de se construírem estruturas treliçadas de madeira com barras cujas extremidades são cortadas em ângulo reto, utilizando-se os conectores metálicos como elementos de solidarização. Foi desenvolvido um modelo computacional que simulou o comportamento da estrutura sob estas condições e, a partir daí, os resultados foram comparados com os obtidos em modelos de escala 1:1. Os resultados mostraram que o valor do momento que ocorre nos banzos e no tramo central da treliça foi afetado, no modelo avaliado, concluindo-se que o corte em ângulo pode gerar a necessidade de ter-se banzos e tramos com controle de qualidade mais rigoroso. Entretanto, com relação aos esforços normais nas barras da estrutura, observou-se que não houve alteração significativa, nem no tocante à flambagem do conector metálico, concluindo-se que, apesar do exposto acima, é viável a construção de estruturas com corte reto nas barras que a integram, gerando apenas a necessidade de maior atenção no controle tecnológico.

SHRESTHA e ALBANI (1996) realizaram interessante estudo a respeito dos conectores metálicos e seu comportamento em serviço. Apesar destes serem desenvolvidos para trabalhar apenas com solicitações no plano em que são utilizados, em diversas situações acabam sendo solicitados fora do plano durante o transporte, manuseio e içamento das estruturas. Foi avaliada então a capacidade de quatro diferentes tipos de conectores metálicos, verificando-se que sua resistência, para carregamentos fora do plano da estrutura, é da ordem de $11 \%$ da resistência para carregamentos no plano, com os conectores orientados paralelamente às fibras e paralelamente ao carregamento. Este fato mostra que são necessários cuidados especiais com o transporte e o lançamento de tais estruturas.

GROOM (1996) estudou o efeito da variação cíclica da umidade no comportamento das ligações por chapas com dentes estampados. Este estudo mostra-se bastante relevante, uma vez que não são raras as regiões cujas variações climáticas sejam acentuadas. $\mathrm{O}$ autor conclui em seu trabalho que a variação da umidade produz um significante efeito degradativo no comportamento mecânico destas ligações. Parte deste efeito se dá, por exemplo, pelo simples fato de ocorrer um relaxamento da madeira ao redor dos dentes do conector. O estudo mostra, ainda, que uma variação 
cíclica, mesmo não sendo de grande magnitude, das condições de umidade resulta em um decréscimo significativo dos valores de rigidez e de resistência. Neste mesmo trabalho, o autor verificou ainda as alterações de comportamento nas ligações quando do uso de um adesivo, na cravação dos conectores, frente às mesmas condições anteriormente descritas. Verificou que existe um ganho em resistência e em rigidez, mas, sobretudo, o efeito se dá na resistência última da ligação, o que ocorre pois o adesivo diminuirá o efeito de relaxação da madeira junto aos dentes dos conectores.

\subsection{Normas Internacionais}

Como citado anteriormente, em diversos países, a ligação por CDE's em estruturas de madeira já é um sistema muito bem aceito, tendo cada um seus métodos e critérios de dimensionamento.

A seguir serão apresentados alguns dos principais documentos normativos internacionais, métodos de ensaio e critérios de dimensionamento por eles utilizados.

\subsubsection{Os métodos de Ensaio}

Inicialmente, são tratados os métodos de ensaio apresentados em alguns dos mais importantes documentos normativos internacionais.

Vale a pena lembrar que um item em particular é reservado para a NBR 7190/97 Projeto de Estruturas de madeira, da ABNT - Associação Brasileira de Normas Técnicas.

Dentre os documentos normativos internacionais, de início é citado o do ANSI/TPI (American National Standards Institute/Truss Plate Institute), órgão norte-americano responsável pelo desenvolvimento tecnológico na área de conectores metálicos. O 
documento normativo do ANSI/TPI apresenta três modos básicos de ruptura que devem ser verificados em uma ligação por chapas com dentes estampados, sendo estes: por tração na chapa de aço, cisalhamento da chapa de aço e, ainda, o arrancamento dos dentes da chapa da peça de madeira.

De acordo com o TPI-85, os valores das resistências básicas dos conectores metálicos a serem utilizados em ligações de estruturas de madeira devem ser determinados de acordo com método padronizado baseado no carregamento limite que provoca um escorregamento de $0,015 \mathrm{in}$. $(0,38 \mathrm{~mm})$ medido entre o conector e a parte da peça efetivamente resistente, ou ainda, o carregamento limite que provoque um escorregamento de $0,030 \mathrm{in}$. $(0,76 \mathrm{~mm})$ medido entre as peças unidas pelas chapas.

Os corpos-de-prova para os ensaios das ligações devem ser fabricados com espécies disponíveis comercialmente, utilizado-se vinte corpos-de-prova para cada tipo de ensaio, sendo que dez destes devem ser fabricados com os dentes em orientação paralela às fibras e dez com os dentes em orientação a $90^{\circ}$ das fibras.

Os relógios comparadores devem ter sensibilidade de medidas de 0,001 polegada $(0,025 \mathrm{~mm})$, sendo colocados em faces opostas do corpo-de-prova, onde não está a chapa.

O controle da velocidade de carregamento é feito a partir da estimativa da carga máxima, devendo esta ser alcançada em aproximadamente dez minutos, não ultrapassando os limites inferior e superior de 5 e 20 minutos respectivamente. Esses valores podem ser obtidos medindo-se um deslocamento de 0,0035 in/min, correspondente a uma taxa de $0,089 \mathrm{~mm} / \mathrm{min}$ não podendo ainda esta velocidade ser superior a $0,01 \mathrm{in} / \mathrm{min}(0,25 \mathrm{~mm} / \mathrm{min})$. 
Vale a pena notar, ainda, que além dos testes laboratoriais, o TPI-85 recomenda, em seu anexo D, que provas de carga sejam realizadas com elementos em escala 1:1 para ser observado o comportamento dos conectores em serviço.

Os modelos dos corpos-de-prova utilizados e os tipos de falhas encontrados nos ensaios laboratoriais estão apresentados a seguir, juntamente com os modelos das normas inglesa, BS 6948, e européia, Eurocode 5, por tratar-se de procedimentos semelhantes.

Para os ensaios de tração na chapa, o modelo apresentado na norma Inglesa BS 6948, no documento normativo europeu Eurocode 5 e na norma Americana ANSI/TPI é o mesmo, conforme mostrado no esquema abaixo:

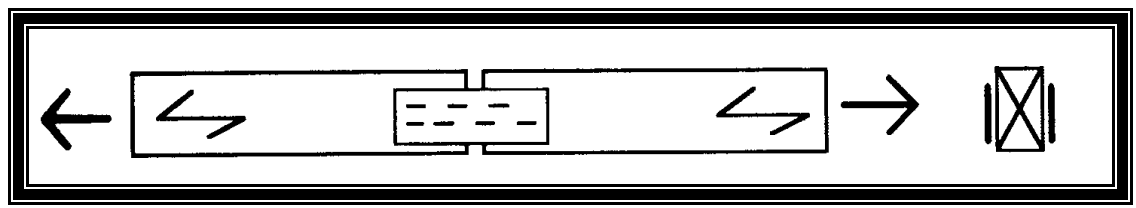

Figura 10 - Arranjo para o ensaio de tração da chapa [Fonte: BARALDI (1996)].

Semelhante ao anterior, para o ensaio de arrancamento da chapa, um mesmo modelo é apresentado em ambos documentos normativos, sendo inclusive o corpo-de-prova de arrancamento paralelo às fibras igual ao de tração da chapa. $\mathrm{O}$ corpo-de-prova para ensaio de arrancamento perpendicular deve ter a configuração:

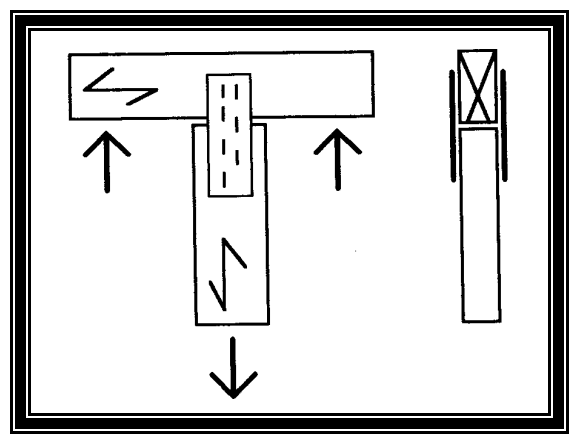

Figura 11 - Arranjo para o ensaio de arrancamento da chapa [Fonte: BARALDI (1996)]. 
Para os ensaios de cisalhamento, três diferentes modelos são apresentados nos documentos normativos citados, conforme se apresenta a seguir:

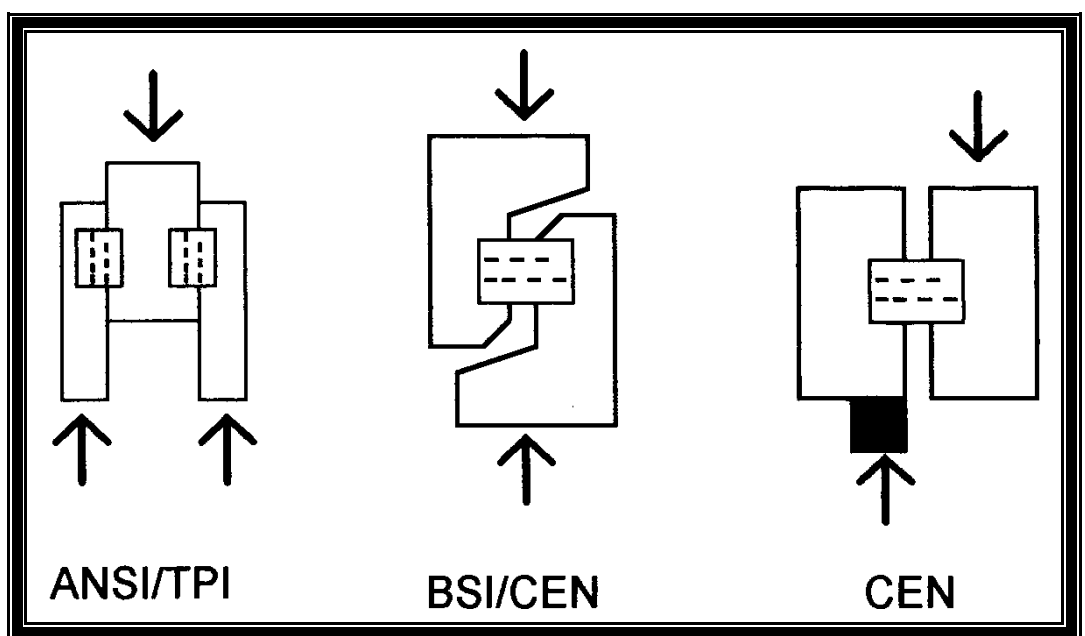

Figura 12 - Arranjos para o ensaio de cisalhamento da chapa [Fonte: BARALDI (1996)].

\subsubsection{Os Critérios de Dimensionamento}

Quanto aos critérios de dimensionamento, três documentos normativos relevantes ao estudo em questão são considerados: o canadense, o europeu e o chileno.

Primeiramente, é abordada a norma canadense, a Canadian Standards Association - CSA S347 - Methods of test for evaluation of truss plate used in lamber joints. De acordo com essa norma, o dimensionamento das ligações é feito levando em conta alguns parâmetros: as espécies de madeira utilizadas, a orientação dos conectores em relação ao carregamento aplicado, a orientação do carregamento em relação às fibras da madeira e a orientação dos conectores em relação às forças de cisalhamento.

A partir destes, serão feitas as verificações:

$\checkmark$ Resistência última ao arrancamento dos dentes dos conectores. 
$\checkmark$ Resistência à tração dos conectores.

$\checkmark$ Resistência dos conectores ao esforço cortante.

Estado limite de utilização, devendo os efeitos do carregamento ser inferiores, ou no mínimo, iguais à resistência ao arrancamento dos dentes do conector.

É importante também citar o Eurocode 5 - Design of timber structures - Part 1-1: General rules and rules for buildings que, em seu anexo D, apresenta os critérios de dimensionamento para as ligações por chapas com dentes estampados. Segundo este documento normativo, devem ser analisados os seguintes aspectos:

$\checkmark$ capacidade resistente dos conectores.

$\checkmark$ resistência de ancoragem.

$\checkmark$ resistência da ligação ao arrancamento.

$\checkmark$ resistência do conector aos esforços solicitantes (verificando-se tração, compressão e momento).

Ainda pode ser citada, quanto ao dimensionamento das ligações por chapas com dentes estampados, a NCH 1198 - Madera - Construcciones de Madera - Calculo, do Instituto Nacional de Normalización - Chile. Como nos casos anteriores, uma série de recomendações de caráter genérico é feita para que se possa realizar a ligação por conectores metálicos, entre elas, a necessidade de que existam dois conectores por ligação, sendo um de cada lado das peças ligadas; de que não haja deformação da peça ligada; de que todos os dentes da chapa penetrem perpendicularmente à madeira.

Além disso, é exigido que os elementos estruturais ligados tenham a mesma espessura nominal, não se permitindo diferenças maiores do que $1 \mathrm{~mm}$.

Para o dimensionamento efetivo das ligações, as seguintes características são consideradas: 
$\checkmark$ Resistência máxima dos dentes da chapa, em $\mathrm{N} / \mathrm{mm}^{2}$ de superfície de ancoragem, em função do ângulo formado entre a força atuante e a orientação da chapa e das fibras da madeira com esta força.

$\checkmark$ Resistência máxima da chapa à tração ou compressão, expressa em $\mathrm{N} / \mathrm{mm}$ de comprimento da seção transversal da chapa.

$\checkmark$ Resistência máxima da chapa ao cisalhamento.

As respectivas resistências das chapas são afetadas no projeto por fatores de modificação, aplicados em função da duração do carregamento aplicado, existência e/ou tipo de tratamento químico da madeira utilizada, quantidade de umidade e excentricidade de cargas.

\subsection{NBR 7190/1997 - Projetos de Estruturas de Madeira}

A atual norma brasileira para projeto de estruturas de madeira, a NBR 7190/1997, documento baseado no método dos estados limites, no que se refere às ligações por chapas com dentes estampados, não explicita os critérios para seu dimensionamento, trazendo em seu anexo $\mathrm{C}$ apenas um roteiro para a realização dos ensaios para verificação do desempenho das citadas ligações.

Nesse contexto, deve ser citado o trabalho desenvolvido por BARALDI (1996), no qual são sugeridos os métodos de ensaio das ligações em estruturas de madeira por chapas com dentes estampados, a partir dos modos de ruptura a que estas ligações estão sujeitas.

Três modos básicos de ruptura foram identificados e recomendadas suas verificações, sendo:

- Tração da chapa;

- Cisalhamento da chapa; 
- Arrancamento dos dentes da chapa da peça de madeira.

As sugestões de BARALDI foram incorporadas no texto da NBR 7190/1997.

De acordo com a NBR 7190/97, "a resistência das ligações por chapas com dentes estampados é definida pelo escoamento da chapa metálica ou pelo início de arrancamento da chapa, ou por qualquer fenômeno de ruptura da madeira, não se tomando valor maior que a carga aplicada ao corpo-de-prova para uma deformação específica residual da ligação de $2 \%$, medida em uma base de referência padronizada, igual ao comprimento da chapa metálica na direção do esforço aplicado", conforme é mostrado nas figuras abaixo:

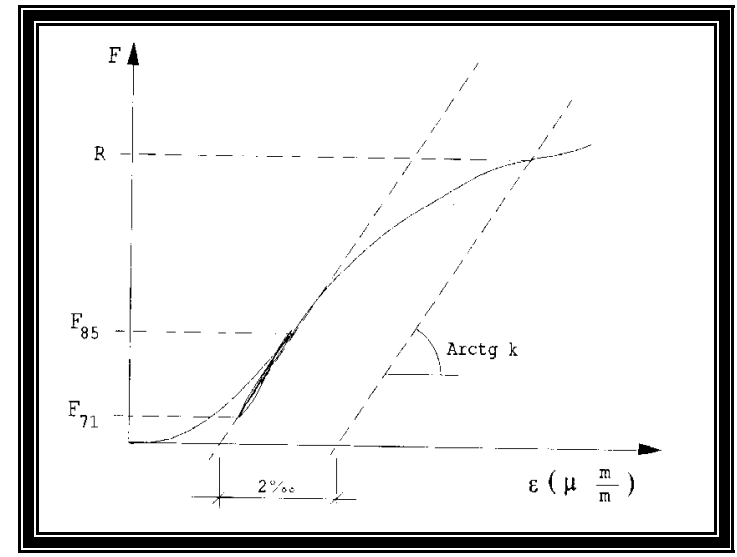

Figura 13 - Resistência e Rigidez de uma ligação por CDE [Fonte: NBR 7190/97].

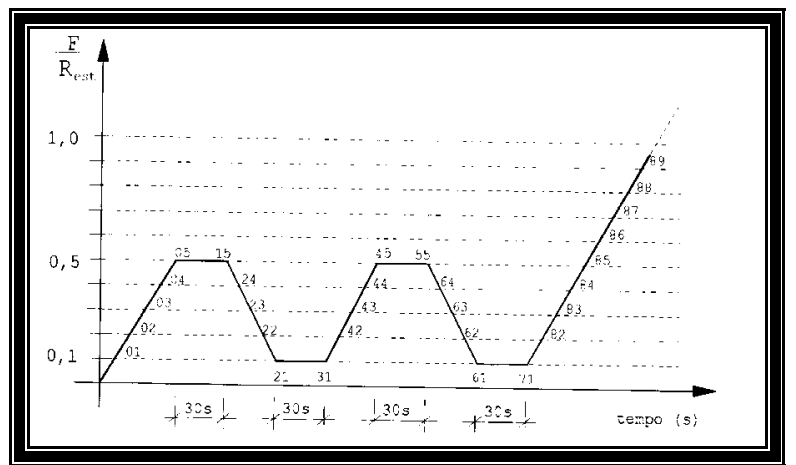

Figura 14 - Diagrama com os ciclos de carregamento [Fonte: NBR 7190/97]. 
Na figura acima estão apresentados os gráficos utilizados para a determinação da resistência (R), sendo esta obtida no ponto de intersecção da reta paralela, traçada a $2 \%$ do trecho linear do diagrama, com o diagrama força $\mathrm{x}$ deformação específica e da rigidez $(\mathrm{K})$ de uma ligação por chapas com dentes estampados e ainda os ciclos de carregamento que devem ser aplicados aos corpos-de-prova na realização dos ensaios.

As seguintes resistências devem ser determinadas nos ensaios:

- Resistência de ancoragem na direção paralela às fibras;

- Resistência de ancoragem na direção normal às fibras;

- Resistência ao escoamento da chapa no ensaio de tração paralela;

- Resistência ao escoamento da chapa no ensaio de tração normal;

- Resistência ao escoamento da chapa no ensaio de compressão paralela;

- Resistência ao escoamento da chapa no ensaio de compressão normal;

- Resistência ao cisalhamento da chapa paralelo às fibras;

- Resistência ao cisalhamento da chapa normal às fibras.

Os arranjos para a realização dos ensaios segundo a NBR 7190/97 estão apresentados a seguir:

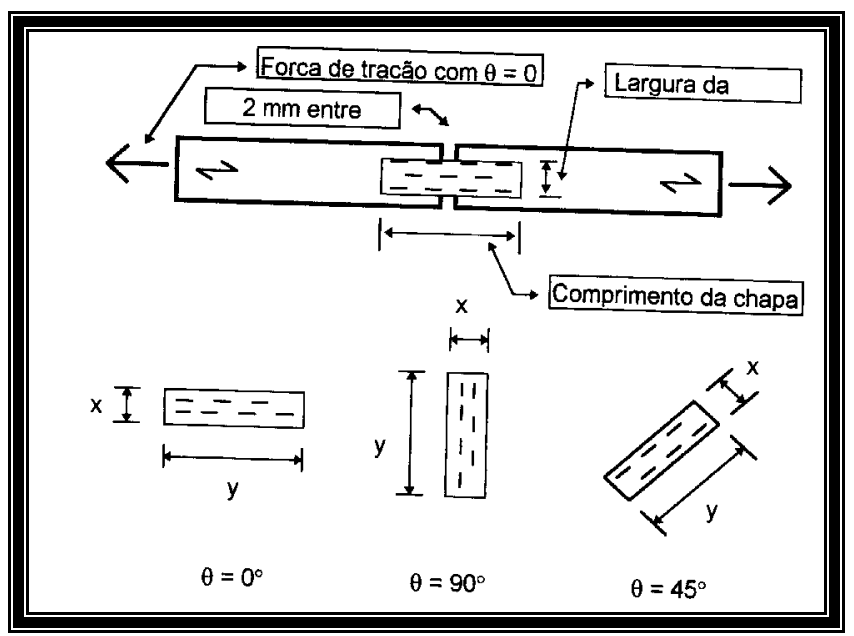

Figura 15 - Arranjo para os ensaios de tração ou compressão paralela às fibras [Fonte: BARALDI (1996)]. 


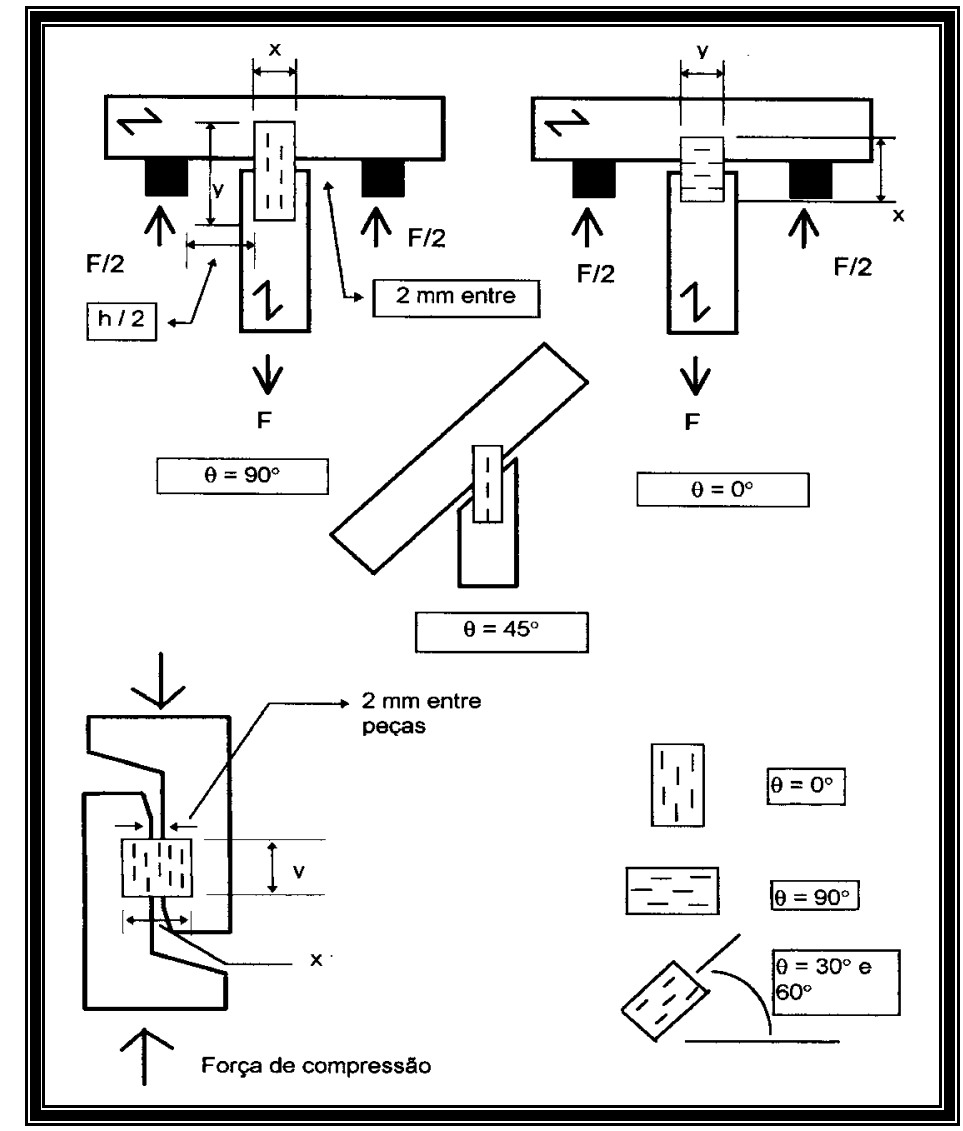

Figura 16 - Arranjo para os ensaios de tração ou compressão normal às fibras e cisalhamento [Fonte: BARALDI (1996)].

Os procedimentos a serem utilizados na realização dos ensaios são:

- As medidas devem ser realizadas com precisão de $0,1 \mathrm{~mm}$;

- As medidas das deformações devem ser realizadas com relógios comparadores ou transdutores de deslocamento, com sensibilidade de 0,01 mm;

- O carregamento aplicado deve ser conforme apresentado em gráfico anexo;

- A resistência estimada deve ser tomada como a carga máxima de ensaio; 
É importante observar que se o valor da resistência estimada diferir do primeiro para mais de dois corpos-de-prova, tal resistência deve ser reavaliada em um novo ensaio.

\subsection{Conclusões sobre a Revisão Bibliográfica}

O levantamento bibliográfico realizado mostra que uma série de aspectos relacionados ao desempenho das ligações entre peças de madeira por CDE têm sido abordados pelos pesquisadores da área.

Um aspecto importante que pôde ser observado através da revisão bibliográfica é que em todos os documentos normativos estudados há uma concordância quanto aos modos de falha da ligação, que são o arrancamento da chapa metálica, a ruptura desta por tração, ou ainda, a ruptura da chapa metálica por cisalhamento.

Entretanto, não foi encontrado nos registros disponíveis, qualquer referência onde a ênfase do trabalho tenha sido avaliar a adequação de um modelo matemático para descrever o comportamento de ligações nas quais o estado limite último seja provocado pelo arrancamento da chapa.

Tal arrancamento, em geral, é imediatamente precedido pelo fato de se ter atingido a resistência última ao embutimento dos dentes da chapa na madeira.

Assim sendo, pode-se considerar que a abordagem principal do trabalho ora apresentado se constitui, efetivamente, numa contribuição para a definição dos critérios de dimensionamento das mencionadas ligações entre peças estruturais de madeira. 


\section{EMBASAMENTO TEÓRICO}

\subsection{Generalidades}

Nas referências bibliográficas consultadas, não se encontrou qualquer abordagem que considerasse todos os modelos matemáticos necessários para explicar o fenômeno da ruptura das ligações entre peças de madeira através dos CDE's. Tais modelos são fundamentais para compreender o comportamento das ligações e para fornecer subsídios que permitam se chegar a alternativas para os critérios de dimensionamento, à luz do método do estados limites, que fundamenta o texto da atual NBR 7190/1997 - Projeto de Estruturas de Madeira, da ABNT.

Observou-se que os modelos tratando da tração e do cisalhamento na chapa não esgotam o assunto, sendo necessário tratar do modelo que envolve o arrancamento da chapa. Este arrancamento, como pôde ser visto nos ensaios preliminares efetuados, se manifesta somente depois de ter sido atingido o estado limite provocado pela resistência ao embutimento dos dentes da chapa, na madeira das peças interligadas. É claro que, para ocorrer este estado limite, não devem ser alcançadas as resistências à tração e ao cisalhamento das chapas.

Deve, também, ser destacado que o estado limite decorrente do arrancamento da chapa (como se explicou) pode acontecer, com alta freqüência, em casos usuais de nós de estruturas treliçadas, como discute SERAPHIM (2001). Entretanto, o autor não equaciona o problema, deixando este procedimento como recomendação básica para o prosseguimento das atividades de pesquisa nesta linha. 
Diante deste fato, optou-se por proceder à sugestão do equacionamento teórico do problema, para subseqüente comprovação a partir da experimentação correspondente, visando avaliar a adequação do modelo proposto.

\subsection{Modelo Matemático}

Considere-se a figura 31, na qual está esquematizada uma ligação tracionada entre duas peças de madeira interligadas por CDE's, aplicadas paralelamente à direção das fibras e da força de tração:

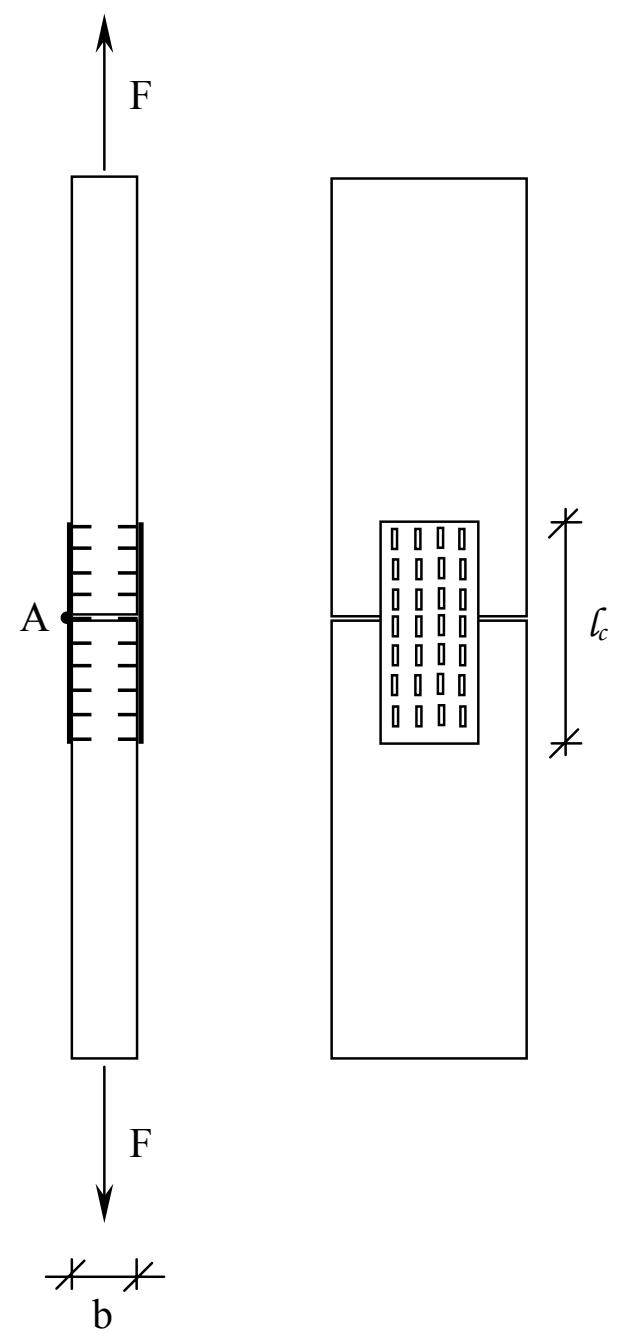

Figura 17 - Esquema de uma ligação tracionada com CDE. 
Isolando-se a chapa, o equilíbrio pode ser proposto como segue:

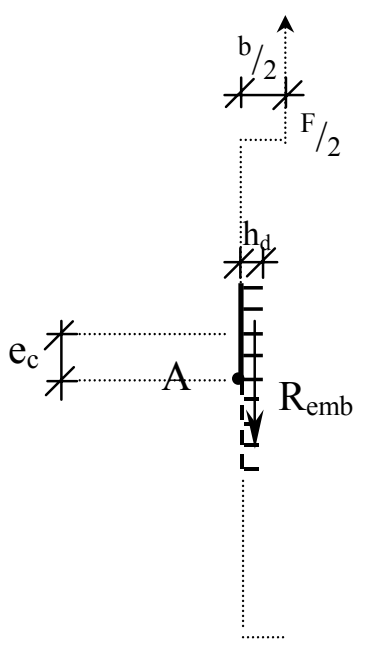

$$
\begin{aligned}
& \Sigma \mathrm{M}_{\mathrm{A}}=0 \\
& \frac{F}{2} * \frac{b}{2}=R_{e m b} * \frac{h_{d}}{2} \\
& R_{e m b}=\frac{n}{2} \cdot h_{d} \cdot e_{d} \cdot \sigma_{e m b}
\end{aligned}
$$

Nas expressões $\mathrm{y}_{1}$ e $\mathrm{y}_{2}$ tem-se:

$\begin{array}{lll}\mathrm{F} & - & \text { Força de tração aplicada } \\ \mathrm{b} & - & \text { Largura das peças interligadas } \\ \mathrm{R}_{\mathrm{emb}} & - & \text { Resultante das forças de embutimento } \\ \mathrm{n} & - & \text { Número de dentes de uma chapa } \\ \mathrm{h}_{\mathrm{d}} & - & \text { Altura do dente } \\ \mathrm{e}_{\mathrm{d}} & - & \text { Espessura do dente } \\ \sigma_{\mathrm{emb}} & - & \text { Tensão atuante de embutimento }\end{array}$

De $y_{1}$ e $y_{2}$, chega-se a:

$$
\begin{aligned}
& \frac{F}{2} \cdot \frac{b}{2}=\frac{n}{2} \cdot h_{d} \cdot e_{d} \cdot \sigma_{e m b} \cdot \frac{h_{d}}{2} \\
& F=\frac{n \cdot e_{d} \cdot h_{d}^{2} \cdot \sigma_{e m b}}{b}
\end{aligned}
$$

No instante em que a tensão de embutimento alcança seu valor máximo $\left(f_{\text {emb }}\right)$, atinge-se a força considerada de ruptura na ligação e é desencadeado o arrancamento da chapa, sem aumento sensível da força aplicada (como se observou nos ensaios). Deste modo, é possível admitir, na ruptura:

$$
F=\frac{n \cdot e_{d} \cdot h_{d}^{2} \cdot f_{e m b, 0}}{b}
$$


Vale registrar que para ângulos $\underline{\alpha}$ quaisquer entre as fibras da madeira e a posição da chapa, pode-se trabalhar com o valor de $\mathrm{f}_{\mathrm{emb}, \alpha}$.

A partir da expressão $\mathrm{y}_{3}$, é possível a determinação de quaisquer das variáveis envolvidas, uma vez conhecidas as demais.

Na prática, a determinação será feita conhecendo-se o valor de cálculo da resistência ao embutimento, nas direções desejadas. Deste modo, determinam-se todos os valores de cálculo da força que será resistida pelos $\underline{\mathrm{n}}$ dentes das chapas utilizadas.

\subsection{Outras Considerações}

Na avaliação experimental da expressão proposta, é importante lembrar:

- A resistência última ao embutimento é um valor superior à chamada resistência convencional ao embutimento, obtida conforme recomendado pela NBR 7190/97. Assim, no desenvolvimento deste trabalho, as comparações serão efetuadas tanto para a condição de resistência última como para a condição de resistência convencional.

- A NBR 7190/97 prescreve quatro classes de resistência para as dicotiledôneas (C20, C30, C40 e C60) e três classes de resistência para as coníferas (C20, C25 e C30). Mesmo sabendo-se que o emprego dos conectores metálicos se verifica com maior freqüência para espécies até a classe $C 40$, neste trabalho foram buscados lotes que atendessem a todas as classes preconizadas.

- Neste trabalho procurou-se, também, focar a parte experimental no tocante às ligações tracionadas, recomendando-se futuras abordagens para as ligações comprimidas. 


\section{MATERIAIS E MÉTODOS}

Neste capítulo estão descritos os materiais, os equipamentos e os métodos adotados na parte experimental do trabalho, bem como na análise dos resultados obtidos.

\subsection{Materiais}

\subsubsection{Madeiras}

Para abranger todas as classes de resistência preconizadas pela NBR 7190/97, foram empregadas espécies das dicotiledôneas e das coníferas.

\subsubsection{Dicotiledôneas}

Cedrilho (C20): Seu nome científico é Erisma sp. Trata-se de espécie tropical, encontrada em quase todas as regiões da Floresta Amazônica, com densidade aparente, a $12 \%$ de umidade, entre 0,55 e $0,60 \mathrm{~g} / \mathrm{cm}^{3}$.

Cambará (C30): Seu nome científico é Erisma uncinatum. Trata-se de espécie tropical, encontrada em quase todas as regiões da Floresta Amazônica, com densidade aparente, a $12 \%$ de umidade, entre 0,65 e $0,70 \mathrm{~g} / \mathrm{cm}^{3}$.

Eucalipto Grandis (C40): Seu nome científico é Eucalyptus grandis. Sua densidade aparente, a $12 \%$ de umidade, pode variar entre 0,7 e $0,9 \mathrm{~g} / \mathrm{cm}^{3}$. É uma 
árvore de reflorestamento que se desenvolve muito bem em regiões de clima tropical a temperado, resistindo até aproximadamente $\left(-5^{\circ} \mathrm{C}\right)$.

Peroba Rosa (C60): Seu nome científico é Aspidosperma polyneuron. Sua densidade aparente, a $12 \%$ de umidade, varia entre 0,8 e $0,9 \mathrm{~g} / \mathrm{cm}^{3}$. É normalmente encontrada em toda a bacia do rio Paraná, abrangendo os Estados de Goiás, Minas Gerais, Mato Grosso do Sul, Mato Grosso, Rondônia, São Paulo, Paraná e Santa Catarina, atingindo Argentina e Paraguai.

\subsubsection{Coníferas}

Pinus Taeda (C20): Seu nome científico é Pinus taeda. Trata-se de espécie com densidade aparente, a $12 \%$ de umidade, variando entre 0,45 a 0,65 $\mathrm{g} / \mathrm{cm}^{3}$. É originária das regiões leste e sudeste dos Estados Unidos, com uma área de ocorrência extensa e descontínua.

Pinus Caribaea (C25): Seu nome científico é Pinus caribaea. Trata-se de espécie com densidade aparente, a $12 \%$ de umidade, variando entre 0,4 e $0,6 \mathrm{~g} / \mathrm{cm}^{3}$, semelhante a outras espécies de Pinus. Sua ocorrência é muito ampla, sendo encontrado naturalmente na costa Atlântica da América Central, de Belize até a Nicarágua.

Pinus Elliottii (C30): Seu nome científico é Pinus elliottii. Trata-se de espécie com densidade aparente, a $12 \%$ de umidade, variando entre 0,45 e $0,6 \mathrm{~g} / \mathrm{cm}^{3}$, semelhante a outras espécies de Pinus. Sua área de ocorrência natural é menos ampla que a do Pinus taeda mas por vezes, ambas se confundem. É geralmente encontrada no sudoeste dos Estados Unidos.

As espécies de Pinus aqui mencionadas são amplamente utilizadas, no Brasil, em florestas plantadas. 


\subsubsection{Conectores metálicos}

$\mathrm{Na}$ experimentação realizada foram utilizados conectores metálicos fabricados pela empresa Gang-Nail do Brasil, com especificação já apresentada anteriormente.

\subsection{Procedimentos de Experimentação}

\subsubsection{Ensaios de Compressão Paralela}

Foram realizados ensaios de compressão paralela às fibras, conforme preconizado na NBR 7190/97 em seu ANEXO B - B.8, para a definição das espécies estudadas em relação às classes de resistência, previstas e apresentadas nas Tabelas 8 e 9 do documento supracitado, e que seguem transcritas a seguir.

\begin{tabular}{|c|c|c|c|c|c|}
\hline \multicolumn{7}{|c|}{ Coníferas } \\
\hline (Valores na condição-padrão de referência U=12\%)
\end{tabular}

Figura 18 - Classes de Resistência das Coníferas segundo a NBR 7190/97.

\begin{tabular}{|c|c|c|c|c|c|}
\hline \multicolumn{7}{|c|}{ Dicotiledôneas } \\
(Valores na condição-padrão de referência $\mathrm{U}=12 \%$ )
\end{tabular}

Figura 19 - Classes de Resistência das Dicotiledôneas segundo a NBR 7190/97. 
As figuras 20 e 21 ilustram a configuração do esquema de um ensaio de compressão paralela às fibras, conforme os desenvolvidos no decorrer da pesquisa
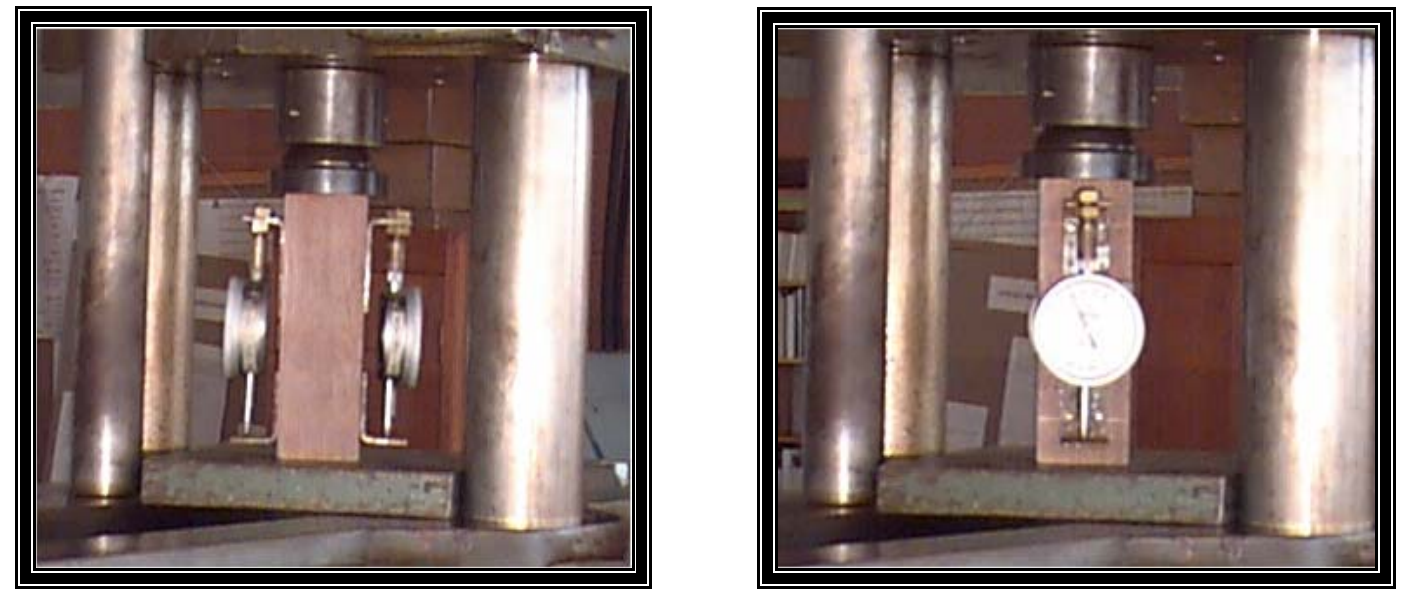

Figuras 20 e 21 - Modelo de ensaio para a avaliação da compressão paralela às fibras em um corpo-de-prova prismático de $5 \times 5 \times 15 \mathrm{~cm}$.

Para a realização dos ensaios de compressão paralela e de tração, foi utilizada uma Máquina Universal de Ensaios AMSLER com capacidade de 250 kN., conforme mostrado a seguir.

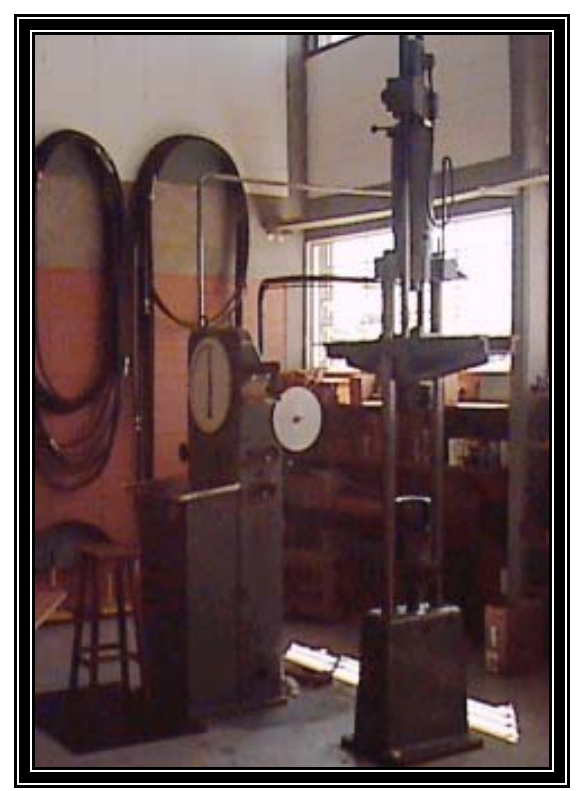

Figura 22 - Máquina Universal de Ensaios. 


\subsubsection{Ensaios de Embutimento}

A realização de tal ensaio deve-se ao fato de que os dentes das chapas metálicas de união ficam em contato com a madeira ligada e quando a ligação é solicitada, estes dentes tendem a embutir nos elementos ligados.

Os ensaios de embutimento foram realizados em uma máquina de ensaios DARTEC com capacidade de $10 \mathrm{kN}$ e atenderam as especificações conforme preconizado na NBR 7190/97 em seu ANEXO B - B17. Detalhes são apresentados nas figuras 23, 24 e 25.

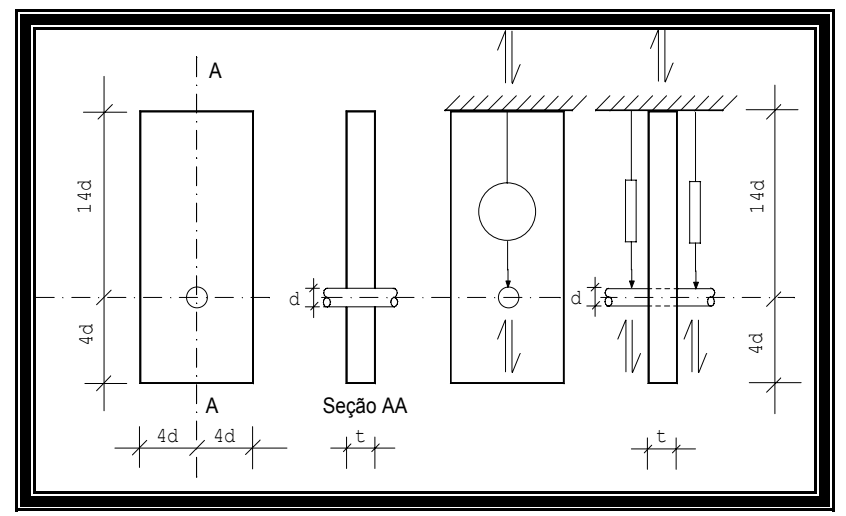

Figura 23 - Esquema de um corpo-de-prova para a realização do ensaio de embutimento segundo a NBR 7190/97.
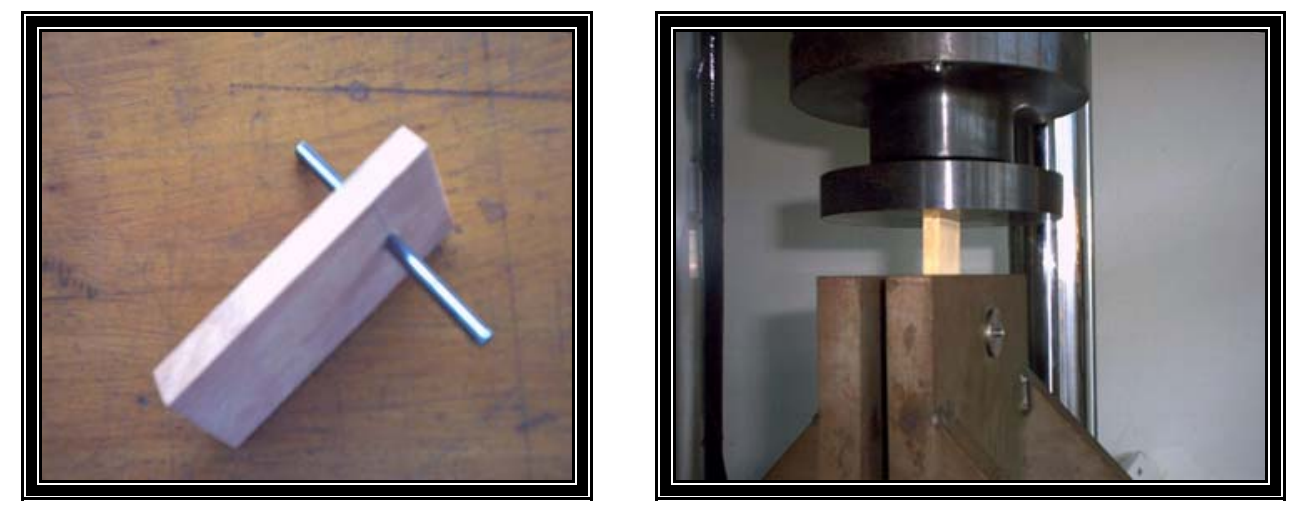

Figuras 24a e 24b - Modelo e montagem de um corpo-de-prova de embutimento em uma máquina de ensaios DARTEC - $10 \mathrm{kN}$. 


\subsubsection{Ensaios de Tração}

Foram realizados, ainda na fase de experimentação, ensaios de tração das ligações por conectores metálicos, ensaios estes que servirão de base para o equacionamento do problema em questão.

Os ensaios foram realizados em conformidade com o que descreve a NBR 7190/97, sendo os corpos-de-prova conforme mostrados na figura a seguir:

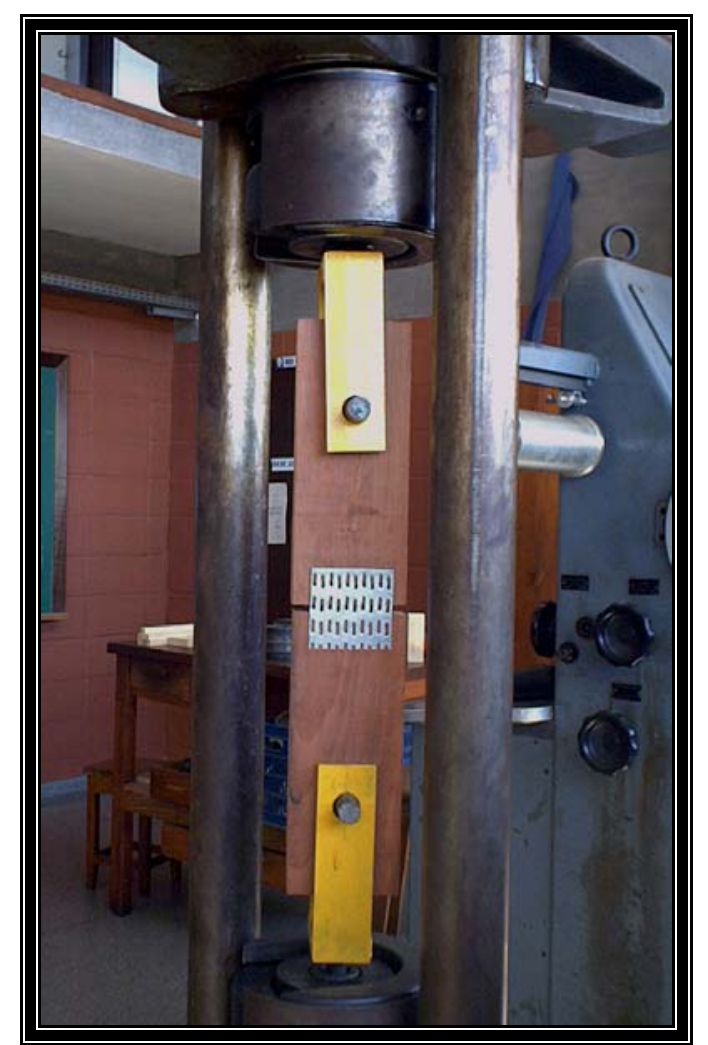

Figura 25 - Montagem de um ensaio de Tração 


\section{APRESENTAÇÃO DE RESULTADOS}

No presente estudo foram ensaiadas, no total, sete diferentes espécies de madeira (nativas e de reflorestamento), sendo três coníferas e quatro dicotiledôneas, as quais foram classificadas conforme mostrado nas figuras a seguir:

Tabelas 1 e 2 - Classificação das Espécies estudadas conforme preconizado pela NBR7190/97 após ensaios de Compressão Paralela.

\begin{tabular}{|l|c|}
\hline \multicolumn{1}{|c|}{ Coníferas } & Classe de Resistência \\
\hline Pinus Taeda & C 20 \\
\hline Pinus Caribea & C 25 \\
\hline Pinus Eliotti & C 30 \\
\hline
\end{tabular}

\begin{tabular}{|l|c|}
\hline \multicolumn{1}{|c|}{ Dicotiledôneas } & Classe de Resistência \\
\hline Cedrilho & C 20 \\
\hline Cambará & C 30 \\
\hline Eucalipto Grandis & C 40 \\
\hline Peroba Rosa & C 60 \\
\hline
\end{tabular}

\subsection{Ensaios de Compressão Paralela às Fibras}

Os resultados apresentados nas tabelas 3 a 9 foram obtidos a partir de ensaios de corpos-de-prova padronizados (unidade: daN/ $/ \mathrm{cm}^{2}$ )

Tabela 3 - Valores de resistência à compressão paralela às fibras: Peroba Rosa

\begin{tabular}{|c|c|}
\hline PEROBA & $\mathrm{f}_{\mathrm{c} 0}\left(\mathrm{daN} / \mathrm{cm}^{2}\right)$ \\
\hline R1 & 657 \\
\hline R2 & 646 \\
\hline R3 & 823 \\
\hline R4 & 647 \\
\hline R5 & 686 \\
\hline R6 & 685 \\
\hline
\end{tabular}


Tabela 4 - Valores de resistência à compressão paralela às fibras: Eucalipto Grandis

\begin{tabular}{|c|c|}
\hline EUCALIPTO GRANDIS & $\mathrm{f}_{\mathrm{c} 0}\left(\mathrm{daN} / \mathrm{cm}^{2}\right)$ \\
\hline $\mathrm{G} 1$ & 482 \\
\hline $\mathrm{G} 2$ & 490 \\
\hline $\mathrm{G} 3$ & 493 \\
\hline $\mathrm{G} 4$ & 429 \\
\hline $\mathrm{G} 5$ & 503 \\
\hline $\mathrm{G} 6$ & 520 \\
\hline
\end{tabular}

Tabela 5 - Valores da resistência à compressão paralela às fibras: Cambará

\begin{tabular}{|c|c|}
\hline CAMBARÁ & $\mathrm{f}_{\mathrm{c} 0}\left(\mathrm{daN} / \mathrm{cm}^{2}\right)$ \\
\hline CA1 & 340 \\
\hline CA2 & 392 \\
\hline CA3 & 376 \\
\hline CA4 & 381 \\
\hline CA5 & 365 \\
\hline CA6 & 338 \\
\hline
\end{tabular}

Tabela 6 - Valores de resistência à compressão paralela às fibras: Cedrilho

\begin{tabular}{|c|c|}
\hline CEDRILHO & $\mathrm{f}_{\mathrm{CO}}\left(\mathrm{daN} / \mathrm{cm}^{2}\right)$ \\
\hline CE1 & 295 \\
\hline CE2 & 290 \\
\hline CE3 & 295 \\
\hline CE4 & 275 \\
\hline CE5 & 270 \\
\hline CE6 & 265 \\
\hline
\end{tabular}

Tabela 7 - Valores de resistência à compressão paralela às fibras: Pinus Elliottii

\begin{tabular}{|c|c|}
\hline PINUS ELLIOTTII & $\mathrm{f}_{\mathrm{c} 0}\left(\mathrm{daN} / \mathrm{cm}^{2}\right)$ \\
\hline $\mathrm{P} 1$ & 385 \\
\hline $\mathrm{P} 2$ & 308 \\
\hline P3 & 381 \\
\hline P4 & 323 \\
\hline P5 & 346 \\
\hline P6 & 358 \\
\hline
\end{tabular}


Tabela 8 - Valores de resistência à compressão paralela às fibras: Pinus Caribaea

\begin{tabular}{|c|c|}
\hline PINUS CARIBAEA & $\mathrm{f}_{\mathrm{c} 0}\left(\mathrm{daN} / \mathrm{cm}^{2}\right)$ \\
\hline PC1 & 296 \\
\hline PC2 & 315 \\
\hline PC3 & 247 \\
\hline PC4 & 252 \\
\hline PC5 & 290 \\
\hline PC6 & 326 \\
\hline
\end{tabular}

Tabela 9 - Valores de resistência à compressão paralela às fibras: Pinus Taeda

\begin{tabular}{|c|c|}
\hline PINUS TAEDA & $\mathrm{f}_{\mathrm{c}}\left(\mathrm{daN} / \mathrm{cm}^{2}\right)$ \\
\hline PT1 & 203 \\
\hline PT2 & 185 \\
\hline PT3 & 262 \\
\hline PT4 & 270 \\
\hline PT5 & 249 \\
\hline PT6 & 261 \\
\hline
\end{tabular}




\subsection{Ensaios de Tração em Corpos-de-prova de Ligações}

\subsubsection{Chapas orientadas paralelamente à direção das fibras}

Os ensaios aqui mencionados foram realizados com força aplicada paralelamente à direção das fibras, arranjo C16 da NBR 7190, chapas paralelas à direção das fibras. Para garantir que a ruptura não ocorresse por tração no conector, foram empregadas chapas com sessenta dentes. Todas as rupturas ocorreram por arrancamento das chapas, decorrentes do fato de ter sido alcançada a resistência última ao embutimento dos dentes na madeira.

Tabela 10 - Valores de resistência última $\left(\mathrm{F}_{\text {exp }}\right)$ da ligação ensaiada e valores da resistência convencional (R) dada pela NBR 7190: Peroba.

\begin{tabular}{|c|c|c|c|}
\hline $\mathbf{C P}$ & $\mathbf{F}_{\text {exp }}$ (daN) & $\mathbf{R}$ (daN) & $\mathbf{R}_{\mathbf{~}} \mathbf{F}_{\text {exp }}$ \\
\hline R1 & 2670 & 2050 & 0,77 \\
\hline R2 & 3020 & 2530 & 0,84 \\
\hline R3 & 3030 & 2610 & 0,86 \\
\hline R4 & 2730 & 2170 & 0,79 \\
\hline R5 & 2950 & 2280 & 0,77 \\
\hline R6 & 3450 & 2810 & 0,81 \\
\hline
\end{tabular}

Tabela 11 - Valores de resistência última $\left(\mathrm{F}_{\text {exp }}\right)$ da ligação ensaiada e valores da resistência convencional (R) dada pela NBR 7190: Eucalipto Grandis.

\begin{tabular}{|c|c|c|c|}
\hline $\mathbf{C P}$ & $\mathbf{F}_{\exp }$ (daN) & $\mathbf{R}$ (daN) & $\mathbf{R} / \mathbf{F}_{\exp }$ \\
\hline G1 & 2610 & 1960 & 0,75 \\
\hline G2 & 2820 & 2040 & 0,72 \\
\hline G3 & 2590 & 2020 & 0,78 \\
\hline G4 & 2470 & 1850 & 0,75 \\
\hline G5 & 2680 & 2100 & 0,78 \\
\hline G6 & 2960 & 2240 & 0,76 \\
\hline
\end{tabular}


Tabela 12 - Valores de resistência última $\left(\mathrm{F}_{\exp }\right)$ da ligação ensaiada e valores da resistência convencional (R) dada pela NBR 7190: Cambará.

\begin{tabular}{|c|c|c|c|}
\hline $\mathbf{C P}$ & $\mathbf{F}_{\text {exp }}(\mathbf{d a N})$ & $\mathbf{R}(\mathbf{d a N})$ & $\mathbf{R} / \mathbf{F}_{\text {exp }}$ \\
\hline CA1 & 1510 & 1080 & 0,72 \\
\hline CA2 & 1520 & 1020 & 0,67 \\
\hline CA3 & 1840 & 1140 & 0,62 \\
\hline CA4 & 2050 & 1430 & 0,70 \\
\hline CA5 & 1610 & 1210 & 0,75 \\
\hline CA6 & 1370 & 960 & 0,70 \\
\hline
\end{tabular}

Tabela 13 - Valores de resistência última $\left(\mathrm{F}_{\exp }\right)$ da ligação ensaiada e valores da resistência convencional (R) dada pela NBR 7190: Cedrilho.

\begin{tabular}{|c|c|c|c|}
\hline $\mathbf{C P}$ & $\mathbf{F}_{\text {exp }}$ (daN) & $\mathbf{R}$ (daN) & $\mathbf{R} / \mathbf{F}_{\text {exp }}$ \\
\hline CE1 & 1260 & 880 & 0,70 \\
\hline CE2 & 1080 & 730 & 0,68 \\
\hline CE3 & 1020 & 810 & 0,79 \\
\hline CE4 & 1210 & 860 & 0,71 \\
\hline CE5 & 990 & 730 & 0,74 \\
\hline CE6 & 1130 & 820 & 0,73 \\
\hline
\end{tabular}

Tabela 14 - Valores de resistência última $\left(\mathrm{F}_{\exp }\right)$ da ligação ensaiada e valores da resistência convencional (R) dada pela NBR 7190: Pinus Elliottii.

\begin{tabular}{|c|c|c|c|}
\hline $\mathbf{C P}$ & $\mathbf{F}_{\text {exp }}(\mathbf{d a N})$ & $\mathbf{R}(\mathbf{d a N})$ & $\mathbf{R} / \mathbf{F}_{\text {exp }}$ \\
\hline PE1 & 1460 & 1030 & 0,71 \\
\hline PE2 & 1350 & 890 & 0,66 \\
\hline PE3 & 1330 & 940 & 0,71 \\
\hline PE4 & 1200 & 840 & 0,70 \\
\hline PE5 & 1280 & 930 & 0,73 \\
\hline PE6 & 1300 & 1020 & 0,78 \\
\hline
\end{tabular}


Tabela 15 - Valores de resistência última $\left(F_{\exp }\right)$ da ligação ensaiada e valores da resistência convencional (R) dada pela NBR 7190: Pinus Caribaea.

\begin{tabular}{|c|c|c|c|}
\hline $\mathbf{C P}$ & $\mathbf{F}_{\text {exp }}$ (daN) & $\mathbf{R}$ (daN) & $\mathbf{R} / \mathbf{F}_{\text {exp }}$ \\
\hline PC1 & 1220 & 950 & 0,78 \\
\hline PC2 & 1240 & 900 & 0,73 \\
\hline PC3 & 890 & 660 & 0,74 \\
\hline PC4 & 980 & 680 & 0,69 \\
\hline PC5 & 1060 & 820 & 0,77 \\
\hline PC6 & 1180 & 830 & 0,70 \\
\hline
\end{tabular}

Tabela 16 - Valores de resistência última $\left(\mathrm{F}_{\exp }\right)$ da ligação ensaiada e valores da resistência convencional (R) dada pela NBR 7190: Pinus Taeda.

\begin{tabular}{|c|c|c|c|}
\hline CP & $\mathbf{F}_{\text {exp }}$ (daN) & $\mathbf{R}$ (daN) & $\mathbf{R} / \mathbf{F}_{\text {exp }}$ \\
\hline PT1 & 870 & 620 & 0,71 \\
\hline PT2 & 820 & 630 & 0,77 \\
\hline PT3 & 930 & 660 & 0,71 \\
\hline PT4 & 850 & 650 & 0,76 \\
\hline PT5 & 940 & 600 & 0,64 \\
\hline PT6 & 750 & 520 & 0,69 \\
\hline
\end{tabular}




\subsubsection{Chapas orientadas perpendicularmente à direção das fibras}

Os ensaios aqui mencionados foram realizados com força aplicada paralelamente à direção das fibras, arranjo C16 da NBR 7190, chapas perpendiculares à direção das fibras. Para garantir que a ruptura não ocorresse por tração no conector, foram empregadas chapas com setenta dentes. Todas as rupturas ocorreram por arrancamento das chapas, decorrentes do fato de ter sido alcançada a resistência última ao embutimento dos dentes na madeira.

Tabela 17 - Valores de resistência última $\left(\mathrm{F}_{\exp }\right)$ da ligação ensaiada e valores da resistência convencional (R) dada pela NBR 7190: Peroba.

\begin{tabular}{|c|c|c|c|}
\hline $\mathbf{C P}$ & $\mathbf{F}_{\exp }(\mathbf{d a N})$ & $\mathbf{R}$ (daN) & $\mathbf{R} / \mathbf{F}_{\exp }$ \\
\hline R1 & 980 & 810 & 0,83 \\
\hline R2 & 1040 & 800 & 0,77 \\
\hline R3 & 1480 & 960 & 0,65 \\
\hline R4 & 1280 & 980 & 0,77 \\
\hline R5 & 1260 & 900 & 0,71 \\
\hline R6 & 1270 & 940 & 0,74 \\
\hline
\end{tabular}

Tabela 18 - Valores de resistência última $\left(\mathrm{F}_{\exp }\right)$ da ligação ensaiada e valores da resistência convencional (R) dada pela NBR 7190: Eucalipto Grandis

\begin{tabular}{|c|c|c|c|}
\hline $\mathbf{C P}$ & $\mathbf{F}_{\exp }$ (daN) & $\mathbf{R}$ (daN) & $\mathbf{R} / \mathbf{F}_{\exp }$ \\
\hline G1 & 960 & 900 & 0,94 \\
\hline G2 & 930 & 840 & 0,90 \\
\hline G3 & 1000 & 820 & 0,82 \\
\hline G4 & 920 & 830 & 0,90 \\
\hline G5 & 1050 & 800 & 0,76 \\
\hline G6 & 1290 & 980 & 0,76 \\
\hline
\end{tabular}


Tabela 19 - Valores de resistência última $\left(\mathrm{F}_{\exp }\right)$ da ligação ensaiada e valores da resistência convencional (R) dada pela NBR 7190: Cambará.

\begin{tabular}{|c|c|c|c|}
\hline $\mathbf{C P}$ & $\mathbf{F}_{\exp }(\mathbf{d a N})$ & $\mathbf{R}(\mathbf{d a N})$ & $\mathbf{R} / \mathbf{F}_{\exp }$ \\
\hline CA1 & 650 & 490 & 0,75 \\
\hline CA2 & 630 & 500 & 0,79 \\
\hline CA3 & 720 & 560 & 0,78 \\
\hline CA4 & 930 & 570 & 0,61 \\
\hline CA5 & 700 & 480 & 0,69 \\
\hline CA6 & 640 & 540 & 0,84 \\
\hline
\end{tabular}

Tabela 20 - Valores de resistência última $\left(\mathrm{F}_{\exp }\right)$ da ligação ensaiada e valores da resistência convencional (R) dada pela NBR 7190: Cedrilho.

\begin{tabular}{|c|c|c|c|}
\hline $\mathbf{C P}$ & $\mathbf{F}_{\text {exp }}$ (daN) & $\mathbf{R}(\mathbf{d a N})$ & $\mathbf{R} / \mathbf{F}_{\text {exp }}$ \\
\hline CE1 & 480 & 350 & 0,73 \\
\hline CE2 & 420 & 310 & 0,74 \\
\hline CE3 & 400 & 350 & 0,88 \\
\hline CE4 & 530 & 340 & 0,64 \\
\hline CE5 & 450 & 400 & 0,89 \\
\hline CE6 & 430 & 350 & 0,81 \\
\hline
\end{tabular}

Tabela 21 - Valores de resistência última $\left(\mathrm{F}_{\exp }\right)$ da ligação ensaiada e valores da resistência convencional (R) dada pela NBR 7190: Pinus Elliottii.

\begin{tabular}{|c|c|c|c|}
\hline $\mathbf{C P}$ & $\mathbf{F}_{\text {exp }}$ (daN) & $\mathbf{R}$ (daN) & $\mathbf{R}_{\mathbf{~}} \mathbf{F}_{\text {exp }}$ \\
\hline PE1 & 560 & 360 & 0,64 \\
\hline PE2 & 580 & 380 & 0,66 \\
\hline PE3 & 530 & 460 & 0,87 \\
\hline PE4 & 590 & 320 & 0,54 \\
\hline PE5 & 560 & 320 & 0,57 \\
\hline PE6 & 560 & 440 & 0,79 \\
\hline
\end{tabular}


Tabela 22 - Valores de resistência última $\left(F_{\exp }\right)$ da ligação ensaiada e valores da resistência convencional (R) dada pela NBR 7190: Pinus Caribaea.

\begin{tabular}{|c|c|c|c|}
\hline $\mathbf{C P}$ & $\mathbf{F}_{\text {exp }}$ (daN) & $\mathbf{R}$ (daN) & $\mathbf{R} / \mathbf{F}_{\text {exp }}$ \\
\hline PC1 & 490 & 360 & 0,73 \\
\hline PC2 & 480 & 390 & 0,81 \\
\hline PC3 & 390 & 300 & 0,77 \\
\hline PC4 & 450 & 260 & 0,58 \\
\hline PC5 & 420 & 260 & 0,62 \\
\hline PC6 & 500 & 330 & 0,66 \\
\hline
\end{tabular}

Tabela 23 - Valores de resistência última $\left(F_{\exp }\right)$ da ligação ensaiada e valores da resistência convencional (R) dada pela NBR 7190: Pinus Taeda.

\begin{tabular}{|c|c|c|c|}
\hline CP & $\mathbf{F}_{\text {exp }}$ (daN) & $\mathbf{R}$ (daN) & $\mathbf{R} / \mathbf{F}_{\text {exp }}$ \\
\hline PT1 & 400 & 260 & 0,65 \\
\hline PT2 & 350 & 230 & 0,66 \\
\hline PT3 & 400 & 250 & 0,63 \\
\hline PT4 & 360 & 270 & 0,75 \\
\hline PT5 & 380 & 280 & 0,74 \\
\hline PT6 & 350 & 200 & 0,57 \\
\hline
\end{tabular}




\subsection{Ensaios de Embutimento}

Nas tabelas 24 a 30 estão apresentados os valores da resistência última ao embutimento paralelo às fibras e da resistência ao embutimento paralelo calculada segundo as recomendações da NBR 7190/1997, com pino de 3mm, para as espécies estudadas.

Tabela 24 - Valores da resistência última ao embutimento paralelo às fibras $\left(f_{\text {emb,últ }}\right)$ e da resistência ao embutimento paralelo $\left(f_{\text {emb, }, 0}\right)$ calculada segundo as recomendações da NBR 7190/97: Peroba Rosa

\begin{tabular}{|c|c|c|c|}
\hline CP & $f_{e m b \text {,ult }}\left(\mathrm{daN} / \mathrm{cm}^{2}\right)$ & $f_{e m b, 0}\left(d a N / c^{2}\right)$ & 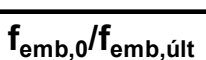 \\
\hline R1 & 870 & 650 & 0,75 \\
\hline R2 & 885 & 640 & 0,72 \\
\hline R3 & 980 & 700 & 0,71 \\
\hline R4 & 930 & 690 & 0,74 \\
\hline R5 & 970 & 720 & 0,74 \\
\hline R6 & 1060 & 780 & 0,74 \\
\hline
\end{tabular}

Tabela 25 - Valores da resistência última ao embutimento paralelo às fibras ( $\left.f_{\text {emb,últ }}\right)$ e da resistência ao embutimento paralelo $\left(f_{\text {emb }, 0}\right)$ calculada segundo as recomendações da NBR 7190/97: Eucalipto Grandis

\begin{tabular}{|c|c|c|c|}
\hline CP & $\mathbf{f}_{\text {emb,últ }}\left(\mathbf{d a N} / \mathbf{c m}^{2}\right)$ & $\mathbf{f}_{\text {emb }, \mathbf{0}}\left(\mathbf{d a N} / \mathbf{c m}^{2}\right)$ & $\mathbf{f}_{\text {emb }, \mathbf{0}} / \mathbf{f}_{\text {emb,últ }}$ \\
\hline $\mathrm{G} 1$ & 720 & 590 & 0,82 \\
\hline G2 & 730 & 570 & 0,78 \\
\hline G3 & 710 & 530 & 0,75 \\
\hline G4 & 680 & 520 & 0,76 \\
\hline G5 & 720 & 530 & 0,74 \\
\hline G6 & 790 & 600 & 0,76 \\
\hline
\end{tabular}


Tabela 26 - Valores da resistência última ao embutimento paralelo às fibras ( $\left.f_{\text {emb,últ }}\right)$ e da resistência ao embutimento paralelo $\left(f_{\text {emb }, 0}\right)$ calculada segundo as recomendações da NBR 7190/97: Cambará

\begin{tabular}{|c|c|c|c|}
\hline $\mathbf{C P}$ & $\mathbf{f}_{\text {emb,últ }}\left(\mathbf{d a N} / \mathbf{c m}^{\mathbf{2}}\right)$ & $\mathbf{f}_{\text {emb, } \mathbf{0}}\left(\mathbf{d a N} / \mathbf{c m}^{2}\right)$ & $\mathbf{f}_{\text {emb, } \mathbf{0}} / \mathbf{f}_{\text {emb,últ }}$ \\
\hline CA1 & 540 & 425 & 0,79 \\
\hline CA2 & 560 & 420 & 0,75 \\
\hline CA3 & 660 & 435 & 0,66 \\
\hline CA4 & 680 & 470 & 0,69 \\
\hline CA5 & 580 & 420 & 0,72 \\
\hline CA6 & 530 & 410 & 0,77 \\
\hline
\end{tabular}

Tabela 27 - Valores da resistência última ao embutimento paralelo às fibras ( $f_{\text {emb,últ }}$ ) e da resistência ao embutimento paralelo $\left(f_{\mathrm{emb}, 0}\right)$ calculada segundo as recomendações da NBR 7190/97: Cedrilho

\begin{tabular}{|c|c|c|c|}
\hline $\mathbf{C P}$ & $\mathbf{f}_{\text {emb,últ }}\left(\mathbf{d a N} / \mathbf{c m}^{\mathbf{2}}\right)$ & $\mathbf{f}_{\text {emb, } \mathbf{0}}\left(\mathbf{d a N} / \mathbf{c m}^{2}\right)$ & $\mathbf{f}_{\text {emb }, \mathbf{0}} / \mathbf{f}_{\text {emb,últ }}$ \\
\hline CE1 & 420 & 295 & 0,70 \\
\hline CE2 & 390 & 290 & 0,74 \\
\hline CE3 & 380 & 295 & 0,78 \\
\hline CE4 & 400 & 275 & 0,69 \\
\hline CE5 & 360 & 270 & 0,75 \\
\hline CE6 & 390 & 265 & 0,68 \\
\hline
\end{tabular}

Tabela 28 - Valores da resistência última ao embutimento paralelo às fibras ( $\left.f_{\text {emb,últ }}\right)$ e da resistência ao embutimento paralelo $\left(f_{\text {emb }, 0}\right)$ calculada segundo as recomendações da NBR 7190/97: Pinus Elliottii

\begin{tabular}{|c|c|c|c|}
\hline $\mathbf{C P}$ & $\mathbf{f}_{\text {emb,ült }}\left(\mathbf{d a N} / \mathbf{c m}^{\mathbf{2}}\right)$ & $\mathbf{f}_{\text {emb }, \mathbf{0}}\left(\mathbf{d a N} / \mathbf{c m}^{2}\right)$ & $\mathbf{f}_{\text {emb, }, 0} / \mathbf{f}_{\text {emb,últ }}$ \\
\hline PE1 & 460 & 320 & 0,70 \\
\hline PE2 & 450 & 325 & 0,72 \\
\hline PE3 & 440 & 340 & 0,77 \\
\hline PE4 & 420 & 290 & 0,69 \\
\hline PE5 & 430 & 295 & 0,69 \\
\hline PE6 & 460 & 340 & 0,74 \\
\hline
\end{tabular}


Tabela 29 - Valores da resistência última ao embutimento paralelo às fibras ( $\left.f_{\text {emb,últ }}\right)$ e da resistência ao embutimento paralelo $\left(f_{\text {emb }, 0}\right)$ calculada segundo as recomendações da NBR 7190/97: Pinus Caribaea

\begin{tabular}{|c|c|c|c|}
\hline CP & $\mathbf{f}_{\text {emb,últ }}\left(\mathbf{d a N} / \mathbf{c m}^{2}\right)$ & $\mathbf{f}_{\text {emb, } \mathbf{0}}\left(\mathbf{d a N} / \mathbf{c m}^{2}\right)$ & $\mathbf{f}_{\text {emb, } \mathbf{0}} / \mathbf{f}_{\text {emb,ült }}$ \\
\hline PC1 & 390 & 270 & 0,69 \\
\hline PC2 & 410 & 295 & 0,72 \\
\hline PC3 & 350 & 260 & 0,74 \\
\hline PC4 & 340 & 245 & 0,72 \\
\hline PC5 & 360 & 240 & 0,67 \\
\hline PC6 & 380 & 270 & 0,71 \\
\hline
\end{tabular}

Tabela 30 - Valores da resistência última ao embutimento paralelo às fibras ( $\left.f_{\text {emb,últ }}\right)$ e da resistência ao embutimento paralelo $\left(f_{\text {emb }, 0}\right)$ calculada segundo as recomendações da NBR 7190/97: Pinus Taeda

\begin{tabular}{|c|c|c|c|}
\hline CP & $\mathbf{f}_{\text {emb,últ }}\left(\mathbf{d a N} / \mathbf{c m}^{2}\right)$ & $\mathbf{f}_{\text {emb }, \mathbf{0}}\left(\mathbf{d a N} / \mathbf{c m}^{2}\right)$ & $\mathbf{f}_{\text {emb, },} / \mathbf{f}_{\text {emb,últ }}$ \\
\hline PT1 & 320 & 220 & 0,69 \\
\hline PT2 & 290 & 215 & 0,74 \\
\hline PT3 & 300 & 210 & 0,70 \\
\hline PT4 & 290 & 200 & 0,69 \\
\hline PT5 & 300 & 205 & 0,68 \\
\hline PT6 & 280 & 185 & 0,66 \\
\hline
\end{tabular}




\section{DISCUSSÃO DE RESULTADOS}

\subsection{Chapas orientadas paralelamente às fibras}

\subsubsection{Embutimento - Resistência Última}

Nas tabelas 31 a 37, a seguir, está apresentada a comparação entre os valores teóricos e os valores experimentais da força máxima resistida pela ligação por CDE, calculados com a resistência última no embutimento, sendo:

$\mathrm{f}_{\text {emb,últ: }}$ Valor da resistência última ao embutimento;

$\mathrm{n}$ : Número de dentes por chapa;

$\mathrm{h}_{\mathrm{d}}$ : Altura dos dentes do conector metálico;

$e_{d}$ : Espessura do dente do conector que atua na direção da força aplicada;

b: Espessura dos elementos ligados

$\mathrm{F}_{\text {exp: }}$ : Valor da força máxima obtida nos ensaios;

$\mathrm{F}_{\text {teor: }}$ Valor da força obtido utilizando-se a expressão apresentada em 4.2.

d: diferença entre $F_{\text {exp }}$ e $F_{\text {teor, }}$ para aplicação do teste de dados pareados

Tabela 31 - Peroba Rosa a $0^{\circ}$ - (Classe C60)

\begin{tabular}{|c|c|c|c|c|c|c|c|c|}
\hline PEROBA & $\mathbf{f}_{\text {emb,últ }}\left(\mathbf{d a N} / \mathbf{c m}^{\mathbf{2}}\right)$ & $\mathbf{n}$ & $\mathbf{h}_{\mathbf{d}}(\mathbf{c m})$ & $\mathbf{e}_{\mathbf{d}}(\mathbf{c m})$ & $\mathbf{b}(\mathbf{c m})$ & $\mathbf{F}_{\exp }(\mathbf{d a N})$ & $\mathbf{F}_{\text {teor }}(\mathbf{d a N})$ & $\mathbf{d}$ \\
\hline $\mathrm{R} 1$ & 870 & 60 & 0,78 & 0,30 & 3,70 & 2670 & 2575 & 95 \\
\hline $\mathrm{R} 2$ & 885 & 60 & 0,78 & 0,30 & 3,44 & 3020 & 2817 & 203 \\
\hline $\mathrm{R} 3$ & 980 & 60 & 0,78 & 0,30 & 3,80 & 3030 & 2824 & 206 \\
\hline $\mathrm{R} 4$ & 930 & 60 & 0,78 & 0,30 & 3,62 & 2730 & 2813 & -83 \\
\hline $\mathrm{R} 5$ & 970 & 60 & 0,78 & 0,30 & 3,66 & 2950 & 2902 & 48 \\
\hline $\mathrm{R} 6$ & 1060 & 60 & 0,78 & 0,30 & 3,40 & 3450 & 3414 & 36 \\
\hline
\end{tabular}


Tabela 32 - Eucalipto Grandis a $0^{\circ}$ - (Classe C40)

\begin{tabular}{|c|c|c|c|c|c|c|c|c|}
\hline EUC. GRANDIS & $\mathbf{f}_{\text {emb,uilt }}\left(\mathbf{d a N} / \mathbf{c m}^{\mathbf{2}}\right)$ & $\mathbf{n}$ & $\mathbf{h}_{\mathbf{d}}(\mathbf{c m})$ & $\mathbf{e}_{\mathbf{d}}(\mathbf{c m})$ & $\mathbf{b}(\mathbf{c m})$ & $\mathbf{F}_{\text {exp }}(\mathbf{d a N})$ & $\mathbf{F}_{\text {teor }}(\mathbf{d a N})$ & $\mathbf{d}$ \\
\hline G1 & 720 & 60 & 0,78 & 0,30 & 3,00 & 2610 & 2628 & -18 \\
\hline G2 & 730 & 60 & 0,78 & 0,30 & 2,96 & 2820 & 2701 & 119 \\
\hline G3 & 710 & 60 & 0,78 & 0,30 & 2,96 & 2590 & 2627 & -37 \\
\hline G4 & 680 & 60 & 0,78 & 0,30 & 3,04 & 2470 & 2450 & 20 \\
\hline G5 & 720 & 60 & 0,78 & 0,30 & 3,02 & 2680 & 2611 & 69 \\
\hline G6 & 790 & 60 & 0,78 & 0,30 & 3,06 & 2960 & 2827 & 133 \\
\hline
\end{tabular}

Tabela 33 - Cambará a $0^{\circ}$ - (Classe C30)

\begin{tabular}{|c|c|c|c|c|c|c|c|c|}
\hline CAMBARÁ & $\mathbf{f}_{\text {emb,ült }}\left(\mathbf{d a N} / \mathbf{c m}^{2}\right)$ & $\mathbf{n}$ & $\mathbf{h}_{\mathbf{d}}(\mathbf{c m})$ & $\mathbf{e}_{\mathbf{d}}(\mathbf{c m})$ & $\mathbf{b}(\mathbf{c m})$ & $\mathbf{F}_{\text {exp }}(\mathbf{d a N})$ & $\mathbf{F}_{\text {teor }}(\mathbf{d a N})$ & $\mathbf{d}$ \\
\hline $\mathrm{C} 1$ & 540 & 60 & 0,78 & 0,30 & 3,85 & 1510 & 1536 & -26 \\
\hline $\mathrm{C} 2$ & 560 & 60 & 0,78 & 0,30 & 3,88 & 1520 & 1581 & -61 \\
\hline $\mathrm{C} 3$ & 660 & 60 & 0,78 & 0,30 & 3,80 & 1840 & 1902 & -62 \\
\hline $\mathrm{C} 4$ & 680 & 60 & 0,78 & 0,30 & 3,80 & 2050 & 1960 & 90 \\
\hline $\mathrm{C} 5$ & 580 & 60 & 0,78 & 0,30 & 3,82 & 1610 & 1663 & -53 \\
\hline $\mathrm{C} 6$ & 530 & 60 & 0,78 & 0,30 & 3,86 & 1370 & 1504 & -134 \\
\hline
\end{tabular}

Tabela 34 - Cedrilho a $0^{\circ}$ - (Classe C20)

\begin{tabular}{|c|c|c|c|c|c|c|c|c|}
\hline CEDRILHO & $\mathbf{f}_{\text {emb,últ }}\left(\mathbf{d a N} / \mathbf{c m}^{\mathbf{2}}\right)$ & $\mathbf{n}$ & $\mathbf{h}_{\mathbf{d}}(\mathbf{c m})$ & $\mathbf{e}_{\mathbf{d}}(\mathbf{c m})$ & $\mathbf{b} \mathbf{( c m})$ & $\mathbf{F}_{\text {exp }}(\mathbf{d a N})$ & $\mathbf{F}_{\text {teor }}(\mathbf{d a N})$ & $\mathbf{d}$ \\
\hline CE1 & 420 & 60 & 0,78 & 0,30 & 3,89 & 1260 & 1182 & 78 \\
\hline CE2 & 390 & 60 & 0,78 & 0,30 & 3,92 & 1080 & 1090 & -10 \\
\hline CE3 & 380 & 60 & 0,78 & 0,30 & 3,82 & 1020 & 1089 & -69 \\
\hline CE4 & 400 & 60 & 0,78 & 0,30 & 3,78 & 1210 & 1159 & 51 \\
\hline CE5 & 360 & 60 & 0,78 & 0,30 & 3,84 & 990 & 1027 & -37 \\
\hline CE6 & 390 & 60 & 0,78 & 0,30 & 3,86 & 1130 & 1106 & 24 \\
\hline
\end{tabular}

Tabela 35 - Pinus Elliottii a $0^{\circ}$ - (Classe C30)

\begin{tabular}{|c|c|c|c|c|c|c|c|c|}
\hline PINUS ELLIOTTII & $\mathbf{f}_{\text {emb,últ }}\left(\mathbf{d a N} / \mathbf{c m}^{\mathbf{2}}\right)$ & $\mathbf{n}$ & $\mathbf{h}_{\mathbf{d}}(\mathbf{c m})$ & $\mathbf{e}_{\mathbf{d}}(\mathbf{c m})$ & $\mathbf{b}(\mathbf{c m})$ & $\mathbf{F}_{\text {exp }}(\mathbf{d a N})$ & $\mathbf{F}_{\text {teor }}(\mathbf{d a N})$ & $\mathbf{d}$ \\
\hline P1 & 460 & 60 & 0,78 & 0,30 & 3,80 & 1460 & 1326 & 134 \\
\hline P2 & 450 & 60 & 0,78 & 0,30 & 3,56 & 1350 & 1384 & -34 \\
\hline P3 & 440 & 60 & 0,78 & 0,30 & 3,74 & 1330 & 1288 & 42 \\
\hline P4 & 420 & 60 & 0,78 & 0,30 & 3,62 & 1200 & 1271 & -71 \\
\hline P5 & 430 & 60 & 0,78 & 0,30 & 3,72 & 1280 & 1266 & 14 \\
\hline P6 & 400 & 60 & 0,78 & 0,30 & 3,86 & 1300 & 1135 & 165 \\
\hline
\end{tabular}


Tabela 36 - Pinus Caribaea a $0^{\circ}$ - (Classe C25)

\begin{tabular}{|c|c|c|c|c|c|c|c|c|}
\hline PINUS CARIBEA & $\mathbf{f}_{\text {emb,últ }}\left(\mathbf{d a N} / \mathbf{c m}^{\mathbf{2}}\right)$ & $\mathbf{n}$ & $\mathbf{h}_{\mathbf{d}}(\mathbf{c m})$ & $\mathbf{e}_{\mathbf{d}}(\mathbf{c m})$ & $\mathbf{b}(\mathbf{c m})$ & $\mathbf{F}_{\text {exp }}(\mathbf{d a N})$ & $\mathbf{F}_{\text {teor }}(\mathbf{d a N})$ & $\mathbf{d}$ \\
\hline PC1 & 390 & 60 & 0,78 & 0,30 & 3,80 & 1220 & 1124 & 96 \\
\hline PC2 & 410 & 60 & 0,78 & 0,30 & 3,86 & 1240 & 1163 & 77 \\
\hline PC3 & 350 & 60 & 0,78 & 0,30 & 3,64 & 890 & 1053 & -163 \\
\hline PC4 & 340 & 60 & 0,78 & 0,30 & 3,56 & 980 & 1046 & -66 \\
\hline PC5 & 360 & 60 & 0,78 & 0,30 & 3,70 & 1060 & 1066 & -6 \\
\hline PC6 & 380 & 60 & 0,78 & 0,30 & 3,78 & 1180 & 1101 & 79 \\
\hline
\end{tabular}

Tabela 37 - Pinus Taeda a $0^{\circ}$ - $($ Classe C20)

\begin{tabular}{|c|c|c|c|c|c|c|c|c|}
\hline PINUS TAEDA & $\mathbf{f}_{\text {emb, últ }}\left(\mathbf{d a N} / \mathbf{c m}^{\mathbf{2}}\right)$ & $\mathbf{n}$ & $\mathbf{h}_{\mathbf{d}}(\mathbf{c m})$ & $\mathbf{e}_{\mathbf{d}}(\mathbf{c m})$ & $\mathbf{b}(\mathbf{c m})$ & $\mathbf{F}_{\text {exp }}(\mathbf{d a N})$ & $\mathbf{F}_{\text {teor }}(\mathbf{d a N})$ & $\mathbf{d}$ \\
\hline PT1 & 320 & 60 & 0,78 & 0,30 & 3,82 & 870 & 917 & -47 \\
\hline PT2 & 290 & 60 & 0,78 & 0,30 & 3,76 & 820 & 845 & -25 \\
\hline PT3 & 300 & 60 & 0,78 & 0,30 & 3,74 & 930 & 878 & 52 \\
\hline PT4 & 290 & 60 & 0,78 & 0,30 & 3,80 & 950 & 836 & 114 \\
\hline PT5 & 300 & 60 & 0,78 & 0,30 & 3,76 & 940 & 874 & 66 \\
\hline PT6 & 280 & 60 & 0,78 & 0,30 & 3,82 & 750 & 803 & -53 \\
\hline
\end{tabular}




\subsubsection{Embutimento - NBR 7190/97}

A seguir está apresentada uma comparação entre os valores teóricos e os valores experimentais da resistência da ligação $(\mathrm{R})$ calculados com a resistência ao embutimento segundo a NBR 7190/1997, sendo:

$f_{\text {emb: }}$ Valor da resistência ao embutimento segundo a NBR 7190/97;

n: Número de dentes por chapa;

$\mathrm{h}_{\mathrm{d}}$ : Altura dos dentes do conector metálico;

$e_{d}$ : Espessura do dente do conector que atua na direção da força aplicada;

b: Espessura dos elementos ligados

$\mathrm{F}_{\text {teor: }}$ : Valor da força obtido utilizando-se a expressão apresentada em 4.2;

R: Valor experimental da força obtido de acordo com a NBR 7190/97.

Tabela 38 - Peroba Rosa a $0^{\circ}$ - (Classe C60)

\begin{tabular}{|c|c|c|c|c|c|c|c|c|}
\hline PEROBA & $\mathbf{f}_{\text {emb }}\left(\mathbf{d a N} / \mathbf{c m}^{2}\right)$ & $\mathbf{n}$ & $\mathbf{h}_{\mathbf{d}}(\mathbf{c m})$ & $\mathbf{e}_{\mathbf{d}}(\mathbf{c m})$ & $\mathbf{b}(\mathbf{c m})$ & $\mathbf{F}_{\text {teor }}(\mathbf{d a N})$ & $\mathbf{R}(\mathbf{d a N})$ & $\mathbf{d}$ \\
\hline R1 & 650 & 60 & 0,78 & 0,30 & 3,70 & 1924 & 2050 & -126 \\
\hline R2 & 640 & 60 & 0,78 & 0,30 & 3,44 & 2037 & 2530 & -493 \\
\hline R3 & 700 & 60 & 0,78 & 0,30 & 3,80 & 2017 & 2610 & -593 \\
\hline R4 & 690 & 60 & 0,78 & 0,30 & 3,62 & 2087 & 2170 & -83 \\
\hline R5 & 720 & 60 & 0,78 & 0,30 & 3,66 & 2154 & 2280 & -126 \\
\hline R6 & 780 & 60 & 0,78 & 0,30 & 3,40 & 2512 & 2810 & -298 \\
\hline
\end{tabular}

Tabela 39 - Eucalipto Grandis a $0^{\circ}$ - (Classe C40)

\begin{tabular}{|c|c|c|c|c|c|c|c|c|}
\hline EUC. GRANDIS & $\mathbf{f}_{\text {emb }}\left(\mathbf{d a N} / \mathbf{c m}^{\mathbf{2}}\right)$ & $\mathbf{n}$ & $\mathbf{h}_{\mathbf{d}}(\mathbf{c m})$ & $\mathbf{e}_{\mathbf{d}}(\mathbf{c m})$ & $\mathbf{b}(\mathbf{c m})$ & $\mathbf{F}_{\text {teor }}(\mathbf{d a N})$ & $\mathbf{R}(\mathbf{d a N})$ & $\mathbf{d}$ \\
\hline G1 & 590 & 60 & 0,78 & 0,30 & 3,00 & 2154 & 1960 & 194 \\
\hline G2 & 570 & 60 & 0,78 & 0,30 & 2,96 & 2109 & 2040 & 69 \\
\hline G3 & 530 & 60 & 0,78 & 0,30 & 2,96 & 1961 & 2020 & -59 \\
\hline G4 & 520 & 60 & 0,78 & 0,30 & 3,04 & 1873 & 1850 & 23 \\
\hline G5 & 530 & 60 & 0,78 & 0,30 & 3,02 & 1922 & 2100 & -178 \\
\hline G6 & 600 & 60 & 0,78 & 0,30 & 3,06 & 2147 & 2240 & -93 \\
\hline
\end{tabular}


Tabela 40 - Cambará a $0^{\circ}$ - (Classe C30)

\begin{tabular}{|c|c|c|c|c|c|c|c|c|}
\hline CAMBARÁ & $\mathbf{f}_{\text {emb }}\left(\mathbf{d a N} / \mathbf{c m}^{2}\right)$ & $\mathbf{n}$ & $\mathbf{h}_{\mathbf{d}}(\mathbf{c m})$ & $\mathbf{e}_{\mathbf{d}}(\mathbf{c m})$ & $\mathbf{b}(\mathbf{c m})$ & $\mathbf{F}_{\text {teor }}(\mathbf{d a N})$ & $\mathbf{R}(\mathbf{d a N})$ & $\mathbf{d}$ \\
\hline $\mathrm{C} 1$ & 425 & 60 & 0,78 & 0,30 & 3,85 & 1209 & 1080 & 129 \\
\hline $\mathrm{C} 2$ & 420 & 60 & 0,78 & 0,30 & 3,88 & 1185 & 1020 & 165 \\
\hline $\mathrm{C} 3$ & 435 & 60 & 0,78 & 0,30 & 3,80 & 1254 & 1140 & 114 \\
\hline $\mathrm{C} 4$ & 470 & 60 & 0,78 & 0,30 & 3,80 & 1354 & 1430 & -76 \\
\hline C5 & 420 & 60 & 0,78 & 0,30 & 3,82 & 1204 & 1210 & -6 \\
\hline C6 & 410 & 60 & 0,78 & 0,30 & 3,86 & 1163 & 960 & 203 \\
\hline
\end{tabular}

Tabela 41 - Cedrilho a $0^{\circ}$ - (Classe C20)

\begin{tabular}{|c|c|c|c|c|c|c|c|c|}
\hline CEDRILHO & $\mathbf{f}_{\text {emb }}\left(\mathbf{d a N} / \mathbf{c m}^{\mathbf{2}}\right)$ & $\mathbf{n}$ & $\mathbf{h}_{\mathbf{d}}(\mathbf{c m})$ & $\mathbf{e}_{\mathbf{d}}(\mathbf{c m})$ & $\mathbf{b}(\mathbf{c m})$ & $\mathbf{F}_{\text {teor }}(\mathbf{d a N})$ & $\mathbf{R}(\mathbf{d a N})$ & $\mathbf{d}$ \\
\hline CE1 & 295 & 60 & 0,78 & 0,30 & 3,89 & 830 & 880 & -50 \\
\hline CE2 & 290 & 60 & 0,78 & 0,30 & 3,92 & 810 & 730 & 80 \\
\hline CE3 & 295 & 60 & 0,78 & 0,30 & 3,82 & 846 & 810 & 36 \\
\hline CE4 & 275 & 60 & 0,78 & 0,30 & 3,78 & 797 & 860 & -63 \\
\hline CE5 & 270 & 60 & 0,78 & 0,30 & 3,84 & 770 & 730 & 40 \\
\hline CE6 & 265 & 60 & 0,78 & 0,30 & 3,86 & 752 & 820 & -68 \\
\hline
\end{tabular}

Tabela 42 - Pinus Elliottii a $0^{\circ}$ - (Classe C30)

\begin{tabular}{|c|c|c|c|c|c|c|c|c|}
\hline PINUS ELLIOTTII & $\mathbf{f}_{\text {emb }}\left(\mathbf{d a N} / \mathbf{c m}^{\mathbf{2}}\right)$ & $\mathbf{n}$ & $\mathbf{h}_{\mathbf{d}}(\mathbf{c m})$ & $\mathbf{e}_{\mathbf{d}}(\mathbf{c m})$ & $\mathbf{b}(\mathbf{c m})$ & $\mathbf{F}_{\text {teor }}(\mathbf{d a N})$ & $\mathbf{R}(\mathbf{d a N})$ & $\mathbf{d}$ \\
\hline P1 & 320 & 60 & 0,78 & 0,30 & 3,80 & 922 & 1020 & -98 \\
\hline P2 & 325 & 60 & 0,78 & 0,30 & 3,56 & 1000 & 1040 & -40 \\
\hline P3 & 340 & 60 & 0,78 & 0,30 & 3,74 & 995 & 950 & 45 \\
\hline P4 & 290 & 60 & 0,78 & 0,30 & 3,62 & 877 & 920 & -43 \\
\hline P5 & 295 & 60 & 0,78 & 0,30 & 3,72 & 868 & 900 & -32 \\
\hline P6 & 340 & 60 & 0,78 & 0,30 & 3,86 & 965 & 900 & 65 \\
\hline
\end{tabular}

Tabela 43 - Pinus Caribaea a $0^{\circ}$ - (Classe C25)

\begin{tabular}{|c|c|c|c|c|c|c|c|c|}
\hline PINUS CARIBEA & $\mathbf{f}_{\text {emb }}\left(\mathbf{d a N} / \mathbf{c m}^{\mathbf{2}}\right)$ & $\mathbf{n}$ & $\mathbf{h}_{\mathbf{d}}(\mathbf{c m})$ & $\mathbf{e}_{\mathbf{d}}(\mathbf{c m})$ & $\mathbf{b}(\mathbf{c m})$ & $\mathbf{F}_{\text {teor }}(\mathbf{d a N})$ & $\mathbf{R}(\mathbf{d a N})$ & $\mathbf{d}$ \\
\hline PC1 & 270 & 60 & 0,78 & 0,30 & 3,80 & 778 & 790 & -12 \\
\hline PC2 & 295 & 60 & 0,78 & 0,30 & 3,86 & 837 & 800 & 37 \\
\hline PC3 & 260 & 60 & 0,78 & 0,30 & 3,64 & 782 & 690 & 92 \\
\hline PC4 & 245 & 60 & 0,78 & 0,30 & 3,56 & 754 & 670 & 84 \\
\hline PC5 & 240 & 60 & 0,78 & 0,30 & 3,70 & 710 & 820 & -110 \\
\hline PC6 & 270 & 60 & 0,78 & 0,30 & 3,78 & 782 & 760 & 22 \\
\hline
\end{tabular}


Tabela 44 - Pinus Taeda a $0^{\circ}$ - (Classe C20)

\begin{tabular}{|c|c|c|c|c|c|c|c|c|}
\hline PINUS TAEDA & $\mathbf{f}_{\text {emb }}\left(\mathbf{d a N} / \mathbf{c m}^{\mathbf{2}}\right)$ & $\mathbf{n}$ & $\mathbf{h}_{\mathbf{d}}(\mathbf{c m})$ & $\mathbf{e}_{\mathbf{d}}(\mathbf{c m})$ & $\mathbf{b}(\mathbf{c m})$ & $\mathbf{F}_{\text {teor }}(\mathbf{d a N})$ & $\mathbf{R}(\mathbf{d a N})$ & $\mathbf{d}$ \\
\hline PT1 & 220 & 60 & 0,78 & 0,30 & 3,82 & 631 & 690 & -59 \\
\hline PT2 & 215 & 60 & 0,78 & 0,30 & 3,76 & 626 & 700 & -74 \\
\hline PT3 & 210 & 60 & 0,78 & 0,30 & 3,74 & 615 & 650 & -35 \\
\hline PT4 & 200 & 60 & 0,78 & 0,30 & 3,80 & 576 & 610 & -34 \\
\hline PT5 & 205 & 60 & 0,78 & 0,30 & 3,76 & 597 & 560 & 37 \\
\hline PT6 & 185 & 60 & 0,78 & 0,30 & 3,82 & 530 & 490 & 40 \\
\hline
\end{tabular}




\subsubsection{Avaliação Estatística}

Nas tabelas a seguir, estão apresentados os intervalos de confiança das médias das diferenças entre os valores básicos e experimentais apresentados nas tabelas 31 a 44 .

Tabela 45 - Avaliação Estatística para os resultados obtidos a partir do Embutimento Último

\begin{tabular}{c|l} 
Espécie & \multicolumn{2}{|l}{ Intervalo de Confiança } \\
\hline Peroba Rosa & $-31,7 \leq \mu \leq 200$ \\
\hline Eucalipto Grandis & $-26,6 \leq \mu \leq 122$ \\
\hline Cambará & $-117,9 \leq \mu \leq 36$ \\
\hline Cedrilho & $-51,8 \leq \mu \leq 64$ \\
\hline Pinus Elliottii & $-55,6 \leq \mu \leq 139$ \\
\hline Pinus Caribaea & $-104,4 \leq \mu \leq 110$ \\
\hline Pinus Taeda & $-54,5 \leq \mu \leq 90$ \\
\hline
\end{tabular}

Tabela 46 - Avaliação Estatística para os resultados obtidos a partir do Embutimento segundo a NBR 7190/97

\begin{tabular}{c|l} 
Espécie & \multicolumn{2}{|l}{ Intervalo de Confiança } \\
\hline Peroba Rosa & $-511,1 \leq \mu \leq-61$ \\
\hline Eucalipto Grandis & $-145,3 \leq \mu \leq 131$ \\
\hline Cambará & $-23,9 \leq \mu \leq 201$ \\
\hline Cedrilho & $-71,1 \leq \mu \leq 63$ \\
\hline Pinus Elliottii & $-91,4 \leq \mu \leq 84$ \\
\hline Pinus Caribaea & $-149,4 \leq \mu \leq 84$ \\
\hline Pinus Taeda & $-53,4 \leq \mu \leq 19$ \\
\hline
\end{tabular}


Merecem especial destaque na avaliação estatística apresentada acima os valores obtidos para a espécie Peroba Rosa. Conforme citado no decorrer do presente trabalho, os conectores metálicos obtêm melhor desempenho quando empregados com madeiras de classe até C40. O lote de Peroba Rosa utilizado nos ensaios foi classificado como C60, conforme tabela 1 no Capítulo 7, e o resultado estatístico obtido aponta que neste caso podem, efetivamente, ocorrer dificuldades na cravação das CDE, prejudicando a aplicação do modelo teórico apresentado.

Para as madeiras das outras classes de resistência, entretanto, como o zero pertence a todos os intervalos de confiança calculados (seis amostras por espécie, 95\% de confiabilidade), admite-se que podem ser considerados estatisticamente equivalentes os resultados teóricos e os experimentais para a força máxima nas ligações estudadas. Com isto, fica evidenciada a validade da expressão abaixo para a estimativa da força máxima nas ligações com CDE's.

$$
F=\frac{n \cdot e_{d} \cdot h_{d}^{2} \cdot f_{e m b}}{b}
$$




\subsection{Chapas orientadas perpendicularmente às fibras}

\subsubsection{Embutimento - Resistência Última}

Nas tabelas 47 a 53, a seguir, está apresentada a comparação entre os valores teóricos e os valores experimentais da força máxima resistida pela ligação por CDE, calculados com a resistência última no embutimento, sendo:

$\mathrm{f}_{\text {emb,últ: }}$ Valor da resistência última ao embutimento;

n: Número de dentes por chapa;

$\mathrm{h}_{\mathrm{d}}$ : Altura dos dentes do conector metálico;

$e_{d}$ : Espessura do dente do conector que atua na direção da força aplicada;

b: Espessura dos elementos ligados

$\mathrm{F}_{\text {exp: }}$ : Valor da força máxima obtida nos ensaios;

$\mathrm{F}_{\text {teor: }}$ Valor da força obtido utilizando-se a expressão apresentada em 4.2.

Tabela 47 - Peroba Rosa a $90^{\circ}$ - (Classe C60)

\begin{tabular}{|c|c|c|c|c|c|c|c|c|}
\hline PEROBA & $\mathbf{f}_{\text {emb, últ }}\left(\mathbf{d a N} / \mathbf{c m}^{\mathbf{2}}\right)$ & $\mathbf{n}$ & $\mathbf{h}_{\mathbf{d}}(\mathbf{c m})$ & $\mathbf{e}_{\mathbf{d}}(\mathbf{c m})$ & $\mathbf{b}(\mathbf{c m})$ & $\mathbf{F}_{\text {exp }}(\mathbf{d a N})$ & $\mathbf{F}_{\text {teor }}(\mathbf{d a N})$ & $\mathbf{d}$ \\
\hline $\mathrm{R} 1$ & 870 & 70 & 0,78 & 0,15 & 3,66 & 1420 & 1519 & -99 \\
\hline $\mathrm{R} 2$ & 885 & 70 & 0,78 & 0,15 & 3,58 & 1360 & 1579 & -219 \\
\hline $\mathrm{R} 3$ & 980 & 70 & 0,78 & 0,15 & 3,60 & 1790 & 1739 & 51 \\
\hline $\mathrm{R} 4$ & 930 & 70 & 0,78 & 0,15 & 3,72 & 1560 & 1597 & -37 \\
\hline $\mathrm{R} 5$ & 970 & 70 & 0,78 & 0,15 & 3,74 & 1680 & 1657 & 23 \\
\hline $\mathrm{R} 6$ & 1060 & 70 & 0,78 & 0,15 & 3,66 & 1750 & 1850 & -100 \\
\hline
\end{tabular}

Tabela 48 - Eucalipto Grandis a $90^{\circ}$ - (Classe C40)

\begin{tabular}{|c|c|c|c|c|c|c|c|c|}
\hline EUC. GRANDIS & $\mathbf{f}_{\text {emb,últ }}\left(\mathbf{d a N} / \mathbf{c m}^{2}\right)$ & $\mathbf{n}$ & $\mathbf{h}_{\mathbf{d}}(\mathbf{c m})$ & $\mathbf{e}_{\mathbf{d}}(\mathbf{c m})$ & $\mathbf{b}(\mathbf{c m})$ & $\mathbf{F}_{\exp }(\mathbf{d a N})$ & $\mathbf{F}_{\text {teor }}(\mathbf{d a N})$ & $\mathbf{d}$ \\
\hline G1 & 720 & 70 & 0,78 & 0,15 & 3,15 & 1400 & 1460 & -60 \\
\hline G2 & 730 & 70 & 0,78 & 0,15 & 3,18 & 1350 & 1466 & -116 \\
\hline G3 & 710 & 70 & 0,78 & 0,15 & 3,26 & 1380 & 1391 & -11 \\
\hline G4 & 680 & 70 & 0,78 & 0,15 & 3,20 & 1300 & 1357 & -57 \\
\hline G5 & 720 & 70 & 0,78 & 0,15 & 3,32 & 1480 & 1385 & 95 \\
\hline G6 & 790 & 70 & 0,78 & 0,15 & 3,24 & 1610 & 1558 & 52 \\
\hline
\end{tabular}


Tabela 49 - Cambará a 90 - (Classe C30)

\begin{tabular}{|c|c|c|c|c|c|c|c|c|}
\hline CAMBARÁ & $\mathbf{f}_{\text {emb, últ }}\left(\mathbf{d a N} / \mathbf{c m}^{\mathbf{2}}\right)$ & $\mathbf{n}$ & $\mathbf{h}_{\mathbf{d}}(\mathbf{c m})$ & $\mathbf{e}_{\mathbf{d}}(\mathbf{c m})$ & $\mathbf{b}(\mathbf{c m})$ & $\mathbf{F}_{\text {exp }}(\mathbf{d a N})$ & $\mathbf{F}_{\text {teor }}(\mathbf{d a N})$ & $\mathbf{d}$ \\
\hline $\mathrm{C} 1$ & 540 & 70 & 0,78 & 0,15 & 3,85 & 870 & 896 & -26 \\
\hline $\mathrm{C} 2$ & 560 & 70 & 0,78 & 0,15 & 3,88 & 840 & 922 & -82 \\
\hline $\mathrm{C} 3$ & 660 & 70 & 0,78 & 0,15 & 3,80 & 1160 & 1110 & 50 \\
\hline C4 & 680 & 70 & 0,78 & 0,15 & 3,80 & 1030 & 1143 & -113 \\
\hline C5 & 580 & 70 & 0,78 & 0,15 & 3,82 & 900 & 970 & -70 \\
\hline C6 & 530 & 70 & 0,78 & 0,15 & 3,86 & 950 & 877 & 73 \\
\hline
\end{tabular}

Tabela 50 - Cedrilho a $90^{\circ}$ - $($ Classe C20 $)$

\begin{tabular}{|c|c|c|c|c|c|c|c|c|}
\hline CEDRILHO & $\mathbf{f}_{\text {emb,últ }}\left(\mathbf{d a N} / \mathbf{c m}^{\mathbf{2}}\right)$ & $\mathbf{n}$ & $\mathbf{h}_{\mathbf{d}}(\mathbf{c m})$ & $\mathbf{e}_{\mathbf{d}}(\mathbf{c m})$ & $\mathbf{b} \mathbf{( c m})$ & $\mathbf{F}_{\text {exp }}(\mathbf{d a N})$ & $\mathbf{F}_{\text {teor }}(\mathbf{d a N})$ & $\mathbf{d}$ \\
\hline CE1 & 420 & 70 & 0,78 & 0,15 & 3,82 & 800 & 702 & 98 \\
\hline CE2 & 390 & 70 & 0,78 & 0,15 & 3,88 & 760 & 642 & 118 \\
\hline CE3 & 380 & 70 & 0,78 & 0,15 & 3,90 & 710 & 622 & 88 \\
\hline CE4 & 400 & 70 & 0,78 & 0,15 & 3,90 & 610 & 655 & -45 \\
\hline CE5 & 360 & 70 & 0,78 & 0,15 & 3,92 & 620 & 587 & 33 \\
\hline CE6 & 390 & 70 & 0,78 & 0,15 & 3,86 & 680 & 645 & 35 \\
\hline
\end{tabular}

Tabela 51 - Pinus Elliottii a $90^{\circ}$ - (Classe C30)

\begin{tabular}{|c|c|c|c|c|c|c|c|c|}
\hline PINUS ELLIOTTII & $\mathbf{f}_{\text {emb,últ }}\left(\mathbf{d a N} / \mathbf{c m}^{\mathbf{2}}\right)$ & $\mathbf{n}$ & $\mathbf{h}_{\mathbf{d}}(\mathbf{c m})$ & $\mathbf{e}_{\mathbf{d}}(\mathbf{c m})$ & $\mathbf{b}(\mathbf{c m})$ & $\mathbf{F}_{\text {exp }}(\mathbf{d a N})$ & $\mathbf{F}_{\text {teor }}(\mathbf{d a N})$ & $\mathbf{d}$ \\
\hline P1 & 460 & 70 & 0,78 & 0,15 & 3,80 & 820 & 773 & 47 \\
\hline P2 & 450 & 70 & 0,78 & 0,15 & 3,56 & 830 & 807 & 23 \\
\hline P3 & 440 & 70 & 0,78 & 0,15 & 3,74 & 760 & 752 & 8 \\
\hline P4 & 420 & 70 & 0,78 & 0,15 & 3,62 & 690 & 741 & -51 \\
\hline P5 & 430 & 70 & 0,78 & 0,15 & 3,72 & 680 & 738 & -58 \\
\hline P6 & 400 & 70 & 0,78 & 0,15 & 3,86 & 620 & 662 & -42 \\
\hline
\end{tabular}

Tabela 52 - Pinus Caribaea a $90^{\circ}$ - (Classe C25)

\begin{tabular}{|c|c|c|c|c|c|c|c|c|}
\hline PINUS CARIBEA & $\mathbf{f}_{\text {emb,últ }}\left(\mathbf{d a N} / \mathbf{c m}^{\mathbf{2}}\right)$ & $\mathbf{n}$ & $\mathbf{h}_{\mathbf{d}}(\mathbf{c m})$ & $\mathbf{e}_{\mathbf{d}}(\mathbf{c m})$ & $\mathbf{b}(\mathbf{c m})$ & $\mathbf{F}_{\text {exp }}(\mathbf{d a N})$ & $\mathbf{F}_{\text {teor }}(\mathbf{d a N})$ & $\mathbf{d}$ \\
\hline PC1 & 390 & 70 & 0,78 & 0,15 & 3,90 & 610 & 639 & -29 \\
\hline PC2 & 410 & 70 & 0,78 & 0,15 & 3,85 & 700 & 680 & 20 \\
\hline PC3 & 350 & 70 & 0,78 & 0,15 & 3,82 & 510 & 585 & -75 \\
\hline PC4 & 340 & 70 & 0,78 & 0,15 & 3,76 & 500 & 578 & -78 \\
\hline PC5 & 360 & 70 & 0,78 & 0,15 & 3,80 & 580 & 605 & -25 \\
\hline PC6 & 380 & 70 & 0,78 & 0,15 & 3,85 & 640 & 631 & 9 \\
\hline
\end{tabular}


Tabela 53 - Pinus Taeda a $90^{\circ}$ - (Classe C20)

\begin{tabular}{|c|c|c|c|c|c|c|c|c|}
\hline PINUS TAEDA & $\mathbf{f}_{\text {emb,últ }}\left(\mathbf{d a N} / \mathbf{c m}^{\mathbf{2}}\right)$ & $\mathbf{n}$ & $\mathbf{h}_{\mathbf{d}}(\mathbf{c m})$ & $\mathbf{e}_{\mathbf{d}}(\mathbf{c m})$ & $\mathbf{b} \mathbf{( \mathbf { c m } )}$ & $\mathbf{F}_{\text {exp }}(\mathbf{d a N})$ & $\mathbf{F}_{\text {teor }}(\mathbf{d a N})$ & $\mathbf{d}$ \\
\hline PT1 & 320 & 70 & 0,78 & 0,15 & 3,85 & 600 & 531 & 69 \\
\hline PT2 & 290 & 70 & 0,78 & 0,15 & 3,68 & 520 & 503 & 17 \\
\hline PT3 & 300 & 70 & 0,78 & 0,15 & 3,80 & 570 & 504 & 66 \\
\hline PT4 & 290 & 70 & 0,78 & 0,15 & 3,82 & 470 & 485 & -15 \\
\hline PT5 & 300 & 70 & 0,78 & 0,15 & 3,78 & 540 & 507 & 33 \\
\hline PT6 & 280 & 70 & 0,78 & 0,15 & 3,80 & 490 & 471 & 19 \\
\hline
\end{tabular}




\subsubsection{Embutimento - NBR 7190/97}

A seguir está apresentada uma comparação entre os valores teóricos e os valores experimentais da resistência da ligação $(\mathrm{R})$ calculados com a resistência ao embutimento segundo a NBR 7190/1997, sendo:

$f_{\text {emb: }}$ Valor da resistência ao embutimento segundo a NBR 7190/97;

n: Número de dentes por chapa;

$\mathrm{h}_{\mathrm{d}}$ : Altura dos dentes do conector metálico;

$e_{d}$ : Espessura do dente do conector que atua na direção da força aplicada;

b: Espessura dos elementos ligados

$\mathrm{F}_{\text {teor: }}$ : Valor da força obtido utilizando-se a expressão apresentada em 4.2;

R: Valor experimental da força obtido de acordo com a NBR 7190/97.

Tabela 54 - Peroba Rosa a $90^{\circ}$ - (Classe C60)

\begin{tabular}{|c|c|c|c|c|c|c|c|c|}
\hline PEROBA & $\mathbf{f}_{\text {emb }}\left(\mathbf{d a N} / \mathbf{c m}^{2}\right)$ & $\mathbf{n}$ & $\mathbf{h}_{\mathbf{d}}(\mathbf{c m})$ & $\mathbf{e}_{\mathbf{d}}(\mathbf{c m})$ & $\mathbf{b}(\mathbf{c m})$ & $\mathbf{F}_{\text {teor }}(\mathbf{d a N})$ & $\mathbf{R}(\mathbf{d a N})$ & $\mathbf{d}$ \\
\hline R1 & 650 & 70 & 0,78 & 0,15 & 3,78 & 1099 & 1200 & -102 \\
\hline R2 & 640 & 70 & 0,78 & 0,15 & 3,62 & 1129 & 1240 & -111 \\
\hline R3 & 700 & 70 & 0,78 & 0,15 & 3,76 & 1189 & 1280 & -91 \\
\hline R4 & 690 & 70 & 0,78 & 0,15 & 3,58 & 1231 & 1250 & -19 \\
\hline R5 & 720 & 70 & 0,78 & 0,15 & 3,65 & 1260 & 1300 & -40 \\
\hline R6 & 780 & 70 & 0,78 & 0,15 & 3,68 & 1354 & 1310 & 44 \\
\hline
\end{tabular}

Tabela 55 - Eucalipto Grandis a $90^{\circ}$ - (Classe C40)

\begin{tabular}{|c|c|c|c|c|c|c|c|c|}
\hline EUC. GRANDIS & $\mathbf{f}_{\text {emb }}\left(\mathbf{d a N} / \mathbf{c m}^{\mathbf{2}}\right)$ & $\mathbf{n}$ & $\mathbf{h}_{\mathbf{d}}(\mathbf{c m})$ & $\mathbf{e}_{\mathbf{d}}(\mathbf{c m})$ & $\mathbf{b} \mathbf{( c m})$ & $\mathbf{F}_{\text {teor }}(\mathbf{d a N})$ & $\mathbf{R}(\mathbf{d a N})$ & $\mathbf{d}$ \\
\hline G1 & 590 & 70 & 0,78 & 0,15 & 3,04 & 1240 & 1220 & 20 \\
\hline G2 & 570 & 70 & 0,78 & 0,15 & 3,00 & 1214 & 1130 & 84 \\
\hline G3 & 530 & 70 & 0,78 & 0,15 & 2,95 & 1148 & 1090 & 58 \\
\hline G4 & 520 & 70 & 0,78 & 0,15 & 3,10 & 1072 & 1020 & 52 \\
\hline G5 & 530 & 70 & 0,78 & 0,15 & 3,06 & 1106 & 1130 & -24 \\
\hline G6 & 600 & 70 & 0,78 & 0,15 & 3,10 & 1236 & 1390 & -154 \\
\hline
\end{tabular}


Tabela 56 - Cambará a 90 - (Classe C30)

\begin{tabular}{|c|c|c|c|c|c|c|c|c|}
\hline CAMBARÁ & $\mathbf{f}_{\text {emb }}\left(\mathbf{d a N} / \mathbf{c m}^{\mathbf{2}}\right)$ & $\mathbf{n}$ & $\mathbf{h}_{\mathbf{d}}(\mathbf{c m})$ & $\mathbf{e}_{\mathbf{d}}(\mathbf{c m})$ & $\mathbf{b}(\mathbf{c m})$ & $\mathbf{F}_{\text {teor }}(\mathbf{d a N})$ & $\mathbf{R}(\mathbf{d a N})$ & $\mathbf{d}$ \\
\hline $\mathrm{C} 1$ & 425 & 70 & 0,78 & 0,15 & 3,90 & 696 & 700 & -4 \\
\hline $\mathrm{C} 2$ & 420 & 70 & 0,78 & 0,15 & 3,86 & 695 & 610 & 85 \\
\hline $\mathrm{C} 3$ & 435 & 70 & 0,78 & 0,15 & 3,88 & 716 & 650 & 66 \\
\hline $\mathrm{C} 4$ & 470 & 70 & 0,78 & 0,15 & 3,86 & 778 & 880 & -102 \\
\hline $\mathrm{C} 5$ & 420 & 70 & 0,78 & 0,15 & 3,80 & 706 & 590 & 116 \\
\hline $\mathrm{C} 6$ & 410 & 70 & 0,78 & 0,15 & 3,85 & 680 & 620 & 60 \\
\hline
\end{tabular}

Tabela 57 - Cedrilho a $90^{\circ}$ - (Classe C20)

\begin{tabular}{|c|c|c|c|c|c|c|c|c|}
\hline CEDRILHO & $\mathbf{f}_{\text {emb }}\left(\mathbf{d a N} / \mathbf{c m}^{\mathbf{2}}\right)$ & $\mathbf{n}$ & $\mathbf{h}_{\mathbf{d}}(\mathbf{c m})$ & $\mathbf{e}_{\mathbf{d}}(\mathbf{c m})$ & $\mathbf{b} \mathbf{( c m})$ & $\mathbf{F}_{\text {teor }}(\mathbf{d a N})$ & $\mathbf{R}(\mathbf{d a N})$ & $\mathbf{d}$ \\
\hline CE1 & 295 & 70 & 0,78 & 0,15 & 3,92 & 481 & 570 & -89 \\
\hline CE2 & 290 & 70 & 0,78 & 0,15 & 3,92 & 473 & 500 & -27 \\
\hline CE3 & 295 & 70 & 0,78 & 0,15 & 3,86 & 488 & 500 & -12 \\
\hline CE4 & 275 & 70 & 0,78 & 0,15 & 3,84 & 457 & 480 & -23 \\
\hline CE5 & 270 & 70 & 0,78 & 0,15 & 3,86 & 447 & 470 & -23 \\
\hline CE6 & 265 & 70 & 0,78 & 0,15 & 3,90 & 434 & 410 & 24 \\
\hline
\end{tabular}

Tabela 58 - Pinus Elliottii a $90^{\circ}$ - $($ Classe C30 $)$

\begin{tabular}{|c|c|c|c|c|c|c|c|c|}
\hline PINUS ELLIOTTII & $\mathbf{f}_{\text {emb }}\left(\mathbf{d a N} / \mathbf{c m}^{\mathbf{2}}\right)$ & $\mathbf{n}$ & $\mathbf{h}_{\mathbf{d}}(\mathbf{c m})$ & $\mathbf{e}_{\mathbf{d}}(\mathbf{c m})$ & $\mathbf{b}(\mathbf{c m})$ & $\mathbf{F}_{\text {teor }}(\mathbf{d a N})$ & $\mathbf{R}(\mathbf{d a N})$ & $\mathbf{d}$ \\
\hline P1 & 320 & 70 & 0,78 & 0,15 & 3,88 & 527 & 480 & 47 \\
\hline P2 & 325 & 70 & 0,78 & 0,15 & 3,90 & 532 & 520 & 12 \\
\hline P3 & 340 & 70 & 0,78 & 0,15 & 3,76 & 578 & 600 & -22 \\
\hline P4 & 290 & 70 & 0,78 & 0,15 & 3,82 & 485 & 520 & -35 \\
\hline P5 & 295 & 70 & 0,78 & 0,15 & 3,85 & 489 & 540 & -51 \\
\hline P6 & 340 & 70 & 0,78 & 0,15 & 3,90 & 557 & 640 & -83 \\
\hline
\end{tabular}

Tabela 59 - Pinus Caribaea a $90^{\circ}$ - (Classe C25)

\begin{tabular}{|c|c|c|c|c|c|c|c|c|}
\hline PINUS CARIBEA & $\mathbf{f}_{\text {emb }}\left(\mathbf{d a N} / \mathbf{c m}^{\mathbf{2}}\right)$ & $\mathbf{n}$ & $\mathbf{h}_{\mathbf{d}}(\mathbf{c m})$ & $\mathbf{e}_{\mathbf{d}}(\mathbf{c m})$ & $\mathbf{b}(\mathbf{c m})$ & $\mathbf{F}_{\text {teor }}(\mathbf{d a N})$ & $\mathbf{R}(\mathbf{d a N})$ & $\mathbf{d}$ \\
\hline PC1 & 270 & 70 & 0,78 & 0,15 & 3,82 & 452 & 490 & -38 \\
\hline PC2 & 295 & 70 & 0,78 & 0,15 & 3,90 & 483 & 610 & -127 \\
\hline PC3 & 265 & 70 & 0,78 & 0,15 & 3,80 & 445 & 420 & 25 \\
\hline PC4 & 245 & 70 & 0,78 & 0,15 & 3,82 & 410 & 380 & 30 \\
\hline PC5 & 240 & 70 & 0,78 & 0,15 & 3,80 & 403 & 360 & 43 \\
\hline PC6 & 270 & 70 & 0,78 & 0,15 & 3,86 & 447 & 540 & -93 \\
\hline
\end{tabular}


Tabela 60 - Pinus Taeda a $90^{\circ}$ - (Classe C20)

\begin{tabular}{|c|c|c|c|c|c|c|c|c|}
\hline PINUS CARIBEA & $\mathbf{f}_{\text {emb }}\left(\mathbf{d a N} / \mathbf{c m}^{2}\right)$ & $\mathbf{n}$ & $\mathbf{h}_{\mathbf{d}}(\mathbf{c m})$ & $\mathbf{e}_{\mathbf{d}}(\mathbf{c m})$ & $\mathbf{b}(\mathbf{c m})$ & $\mathbf{F}_{\text {teor }}(\mathbf{d a N})$ & $\mathbf{R}(\mathbf{d a N})$ & $\mathbf{d}$ \\
\hline PC1 & 220 & 70 & 0,78 & 0,15 & 3,82 & 368 & 315 & 53 \\
\hline PC2 & 215 & 70 & 0,78 & 0,15 & 3,90 & 352 & 329 & 23 \\
\hline PC3 & 210 & 70 & 0,78 & 0,15 & 3,80 & 353 & 381 & -28 \\
\hline PC4 & 200 & 70 & 0,78 & 0,15 & 3,82 & 334 & 301 & 33 \\
\hline PC5 & 205 & 70 & 0,78 & 0,15 & 3,80 & 345 & 309 & 36 \\
\hline PC6 & 185 & 70 & 0,78 & 0,15 & 3,86 & 306 & 247 & 59 \\
\hline
\end{tabular}




\subsubsection{Avaliação Estatística}

Nas tabelas a seguir, estão apresentados os intervalos de confiança das médias das diferenças entre os valores básicos e experimentais apresentados nas tabelas 47 a 60 .

Tabela 61 - Avaliação Estatística para os resultados obtidos a partir do Embutimento Último

\begin{tabular}{c|ccc} 
Espécie & \multicolumn{3}{|l}{ Intervalo de Confiança } \\
\hline Peroba Rosa & $-67 \leq \mu \leq 39$ \\
\hline Eucalipto Grandis & $-98 \leq \mu \leq 64$ \\
\hline Cambará & $-107 \leq \mu \leq 51$ \\
\hline Cedrilho & $-8 \leq \mu \leq 118$ \\
\hline Pinus Elliottii & $-58 \leq \mu \leq 35$ \\
\hline Pinus Caribaea & $-73 \leq \mu \leq 13$ \\
\hline Pinus Taeda & $-2 \leq \mu \leq 66$
\end{tabular}

Tabela 62 - Avaliação Estatística para os resultados obtidos a partir do Embutimento segundo a NBR 7190/97

\begin{tabular}{c|ccc} 
Espécie & \multicolumn{2}{|l}{ Intervalo de Confiança } \\
\hline Peroba Rosa & $-116 \leq \mu \leq 10$ \\
\hline Eucalipto Grandis & $-85 \leq \mu \leq 97$ \\
\hline Cambará & $-46 \leq \mu \leq 120$ \\
\hline Cedrilho & $-64 \leq \mu \leq 13$ \\
\hline Pinus Elliottii & $-70 \leq \mu \leq 26$ \\
\hline Pinus Caribaea & $-101 \leq \mu \leq 48$ \\
\hline Pinus Taeda & $-3 \leq \mu \leq 62$ \\
\hline
\end{tabular}


Como o zero pertence a todos os intervalos de confiança calculados (seis amostras por espécie, $95 \%$ de confiabilidade), admite-se que podem ser considerados estatisticamente equivalentes os resultados teóricos e os experimentais para a força máxima nas ligações estudadas. Com isto, fica evidenciada a validade da expressão abaixo, também para as ligações com chapas orientadas perpendicularmente às fibras, para a estimativa da força máxima nas ligações com CDE's.

$$
F=\frac{n \cdot e_{d} \cdot h_{d}^{2} \cdot f_{e m b}}{b}
$$




\section{CONCLUSÕES FINAIS}

Através do estudo e da avaliação dos vários fatores envolvidos no comportamento das ligações em peças de madeira por conectores metálicos com dentes estampados e da ligação propriamente dita, podemos apresentar as seguintes conclusões:

$\mathrm{O}$ estado limite decorrente do arrancamento do $\mathrm{CDE}$, é um dos fenômenos que podem ocorrer com bastante freqüência nas ligações em estudo e é um fator determinante no dimensionamento de tal ligação. Buscou-se no presente estudo promover um equacionamento do problema e a subseqüente experimentação de modo que a falha não ocorresse pela ruptura do conector metálico. Para tal, obtevese, conforme já discorrido no Capítulo 6 do presente trabalho, a equação que segue abaixo (os parâmetros envolvidos já foram explicitados anteriormente):

$$
F=\frac{n \cdot e_{d} \cdot h_{d}^{2} \cdot f_{e m b, 0}}{b}
$$

A expressão fornece estimativas muito satisfatórias no caso das ligações tracionadas, nas quais os conectores metálicos com entes estampados estejam posicionados a $0^{\circ} \mathrm{e}$ a $90^{\circ}$ em relação à direção das fibras e da força aplicada. A validade da expressão ficou evidenciada quer no caso de se trabalhar com os valores últimos da resistência da ligação e da resistência ao embutimento, quer se trate dos valores convencionais (dados pela NBR 7190/1997) da resistência da ligação e da resistência ao embutimento.

Destaca-se que é preciso conhecer o valor da resistência ao embutimento da espécie de madeira para a qual se deseja dimensionar a ligação, e os parâmetros geométricos 
envolvidos no problema para se estimar a força máxima que será resistida por esta ligação.

Fica aqui registrada a sugestão de que se desenvolvam trabalhos futuros a fim de se avaliar a relação entre os valores da resistência ao embutimento paralelo e o da resistência à compressão paralela em uma determinada espécie de madeira.

Embora a NBR 7190/1997 apresente tal relação como sendo $f_{c, 0}=f_{e m b, 0}$, pode-se notar nos ensaios realizados que existe um aumento no valor da resistência ao embutimento conforme se diminui o valor da área de contato do elemento ligante (pinos, parafusos, dentes dos CDE's) com a do elemento resistente (madeira). Para algumas espécies de madeira, como se pode observar na apresentação de resultados, chegou-se a valores de resistência ao embutimento superiores a $25 \%$ do valor da resistência à compressão paralela para tal espécie. 


\section{Referências Bibliográficas}

ALMEIDA, P. A. O. (1997). Critérios de Projeto das Ligações com Chapas de Dentes Estampados. São Paulo: POLI/USP, (Boletim Técnico nº BT/PEF/9718).

AMERICAN NATIONAL STANDARDS INSTITUTE/ TRUSS PLATE INSTITUTE (1995). ANSI/TPI - National design standard for metal plate connected wood truss construction.

ASSOCIAÇÃO BRASILEIRA DE NORMAS TÉCNICAS (1997). NBR 7190 Projeto de Estruturas de Madeira. Rio de Janeiro.

BARALDI, L. T. (1996). Método de ensaio de ligações de estruturas de madeira por chapas com dentes estampados. São Carlos. 105p. Dissertação (Mestrado) Escola de Engenharia de São Carlos, Universidade de São Paulo.

BARROS, O. (1991). Algumas considerações sobre a pré-fabricação de estruturas de madeira para cobertura. São Carlos. 143p. Dissertação (Mestrado) - Escola de Engenharia de São Carlos, Universidade de São Paulo.

BARROS, O. (1992). Considerações sobre a utilização de madeiras na construção de estruturas de cobertura para conjuntos habitacionais. In: ENCONTRO BRASILEIRO EM MADEIRAS E EM ESTRUTURAS DE MADEIRA, 3., São Carlos, 1992. Anais. V.5, p.79-83.

BREUER, H. (1983). Estruturas pré-fabricadas em madeira. In: ENCONTRO BRASILEIRO EM MADEIRAS E EM ESTRUTURAS DE MADEIRA, 1., São Carlos, 1983. Anais. V.4, p.4.1-4.25.

BRITISH STANDARD INSTITUTION (1989). BS 6948 - Methods of test. 
CANADIAN STANDARDS ASSOCIATION (1980). CSA S347 - Methods of test for evaluation of truss plate used in lumber joints.

COMITÉ EUROPÉEN DE NORMALIZATION (1993). EUROCODE 5 - Design of timber structures. Brussels.

EMERSON, R. N.; FRIDLEY, K. J. (1996). Resistance of metal-plate-connected truss joints to dynamic loading. Forest Products Journal. v.46, n.12, p.83-90. May.

GROOM, L. H. (1994). Effect or moisture cycling on truss-plate joint behavior. Forest Products Journal. v.44, n.1, p.21-28. Jan.

INSTITUTO NACIONAL DE NORMALIZACIÓN DEL CHILE. NCH 1198 Madera: Construcciones de Madera-Calculo.

OLIVEIRA, R. M. (1988). Introdução ao estudo da ligação entre peças de madeira através de chapas metálicas estampadas. São Carlos. /Relatórios de Iniciação Científica LaMEM-SET-EESC-USP/

RILEY, J. G.; GEBREMEDHIN, K. G. (1999). An empirical model for predicting the foundation modulus of wood for metal-plate connector teeth. Transactions of the ASAE. v.42, n.11, p.755-760. May.

SERAPHIM, J. H. C.; FRANCO, N. (2001). Ligações de peças de madeira de eucalipto com o uso de chapas metálicas de dentes estampados. Téchne. n.51, p.50-54. Mar/Abr.

SHRESTHA, D.; ALBANI, T. (1996). Out-of-plane capacity of truss connector plates. Forest Products Journal. v.46, n.13, p.79-81. Feb.

SOUZA, M. Divisores de água. Téchne, n.16, 1995, 1. 16-19.

STAHL, D. C.; CRAMER, S. M.; WOLFE, R. W. (1996). Behavior of metal-plateconnected trusses with square-end webs. Forest Products Journal. v.46, n.11, p.78-84. Jun. 
STERN, E. G. (1992). 35 years of experience with certain types of connectors used for the assembly of wood structures and their components. Forest Products Journal, v.42, n.11/12, p.33-45. Nov-Dec.

UJVARI, W. Z. (1983). Ligações em madeiras feitas com conectores dentados “gang-nail”. In: ENCONTRO BRASILEIRO EM MADEIRAS E EM ESTRUTURAS DE MADEIRA, 1., São Carlos. 1983. Anais. v.4, p.7.1-7.26.

VIA, B. K.; ZINK-SHARP, A.; WOESTE, F. E.; DOLAN, J. D. (1999). Relationship between tooth withdrawal strength and specific gravity for metal plate truss connections. Forest Products Journal. v.49, n.24, p.56-63. Jul. 


\section{Obras Consultadas}

GUPTA, R.; GEBREMEDHIN, K. G. (1990). Destructive testing of metal-plateconnected wood truss joints. Journal of Structural Division. v.116, n.7, p.19711982.

MACKENZIE, C.; McNAMARA, R. (1994). Basic working loads for truss plate connector in Pinus Elliottii. In: PACIFIC TIMBER ENGINEERING CONFERENCE, Austrália, 1994. Proceedings. p. 370-378.

McCARTY, M.; WOLFE, R. W. (1987). Assessment of truss plate performance model applied to Southern Pine truss joints. Forest Products Laboratory. Madison, WI. July.

ROSOWSKY, D. V.; REED, T. D.; TYNER, K. G. (1998). Establishing uplift design values for metal connectors in light-frame construction. Journal of Testing and Evaluation. v.26, n.7, p.426-433. Sep. /Resumo/

SKAGGS, T. D.; WOESTE, F. E.; DOLAN, J. D.; LOFERSKI, J. R. (1994). Safety factors for metal-plate-connected wood trusses - theoretical design versus test specifications. Forest Products Journal. v.44, n.39, p.11-18. Sep. /Resumo/

SKAGGS, T. D.; WOESTE, F. E.; LEWIS, S. L. (1995). Steel properties used to manufacture wood truss metal connector plates. Transactions of the ASAE. v.38, n.21, p.187-195. Jan-Feb. /Resumo/ 